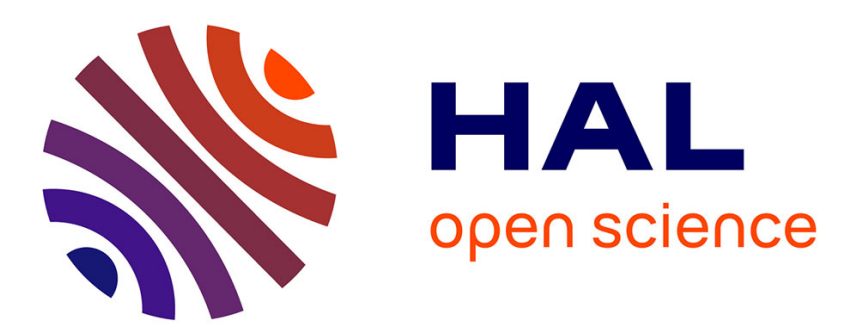

\title{
Climate Adaptation Engineering and Risk-based Design and Management of Infrastructure
}

Mark G. Stewart, Dimitri V. Val, Emilio Bastidas-Arteaga, Alan J. O'Connor, Xiaoming Wang

\section{- To cite this version:}

Mark G. Stewart, Dimitri V. Val, Emilio Bastidas-Arteaga, Alan J. O'Connor, Xiaoming Wang. Climate Adaptation Engineering and Risk-based Design and Management of Infrastructure. Dan M. Frangopol and Yiannis Tsompanakis. Maintenance and Safety of Aging Infrastructure, CRC Press, pp.641-684, 2014, Structures and Infrastructures, 978-0415659420. hal-01065754v2

\section{HAL Id: hal-01065754 \\ https://hal.science/hal-01065754v2}

Submitted on 18 Sep 2014

HAL is a multi-disciplinary open access archive for the deposit and dissemination of scientific research documents, whether they are published or not. The documents may come from teaching and research institutions in France or abroad, or from public or private research centers.
L'archive ouverte pluridisciplinaire HAL, est destinée au dépôt et à la diffusion de documents scientifiques de niveau recherche, publiés ou non, émanant des établissements d'enseignement et de recherche français ou étrangers, des laboratoires publics ou privés. 


\title{
Climate Adaptation Engineering and Risk-Based Design and Management of Infrastructure
}

\author{
M.G. Stewart ${ }^{1}$, D.V. Val ${ }^{2}$, E. Bastidas-Arteaga ${ }^{3}$, A. O' Connor $^{4} \&$ X. Wang $^{5}$ \\ ${ }^{1}$ Centre for Infrastructure Performance and Reliability, The University of Newcastle, Australia. \\ ${ }^{2}$ Institute for Infrastructure and Environment, Heriot-Watt University, UK. \\ ${ }^{3}$ LUNAM Université, Université de Nantes-Ecole Centrale Nantes, GeM, Institute for Research in Civil and \\ Mechanical Engineering/Sea and Littoral Research Institute, France. \\ ${ }^{4}$ Department of Civil, Structural \& Environmental Engineering, Trinity College Dublin, Ireland. \\ ${ }^{5}$ CSIRO Climate Adaptation Flagship and CSIRO Ecosystem Sciences, Commonwealth Science and \\ Industrial Research Organisation, Australia.
}

ABSTRACT: A changing climate may also result in more intense tropical cyclones and storms, more intense rain events and flooding, and other natural hazards. Moreover, increases in $\mathrm{CO}_{2}$ atmospheric concentrations, temperature and humidity will increase corrosion of concrete and steel structures. The chapter will describe how risk-based approaches are well suited to optimising climate adaptation strategies related to the design and maintenance of existing infrastructure. Climate adaptation strategies may include retrofitting or strengthening of existing structures, more frequent inspections, or enhanced designs. An important aspect is assessing at what point in time climate adaptation becomes economically viable. Stochastic methods are used to model infrastructure performance, effectiveness of adaptation strategies, exposure, and costs. These concepts will be illustrated with state-of-the-art research of risk-based assessment of climate adaptation strategies.

\section{INTRODUCTION}

Increases in $\mathrm{CO}_{2}$ atmospheric concentrations may lead to changes in temperature, rainfall, and humidity (IPCC 2007). A changing climate may also result in more intense an/or frequent tropical cyclones and storms, more intense rain events and flooding, sea level rise, and other climaterelated hazards. Moreover, increases in $\mathrm{CO}_{2}$ atmospheric concentrations, temperature and humidity will increase corrosion of concrete and steel structures (Bastidas-Arteaga et al. 2010, 2013, Wang et al. 2012, Stewart et al. 2012a, Nguyen et al. 2013) and affect timber decay (Wang et al. 2012). The performance of existing infrastructure may degrade if subject to more extreme climate-related hazards or accelerated degradation of material properties. In fact, the 
impact of climate change on infrastructure performance is a temporal and spatial process, but most existing models of infrastructure hazard and performance are based on a stationary climate. Moreover, relatively little attention has been paid to quantifying the costs and benefits of adaptation strategies (retrofitting, strengthening, enhanced designs) and assessing at what point in time climate adaptation becomes economically viable. There is increasing research that takes into account the changing climate risk in engineering to reduce the vulnerability of infrastructure - we define this as 'climate adaptation engineering'. The chapter will describe how riskbased approaches are well suited to optimising climate adaptation strategies related to the design and maintenance of existing infrastructure.

Importantly, there has also been significantly more emphasis on impact modelling than climate adaptation engineering modelling. This is understandable when the current political and social environment is focused on mitigating (reducing) $\mathrm{CO}_{2}$ emissions as the 'best' way to reduce the impact of a changing climate. However, even under an optimistic scenario where $\mathrm{CO}_{2}$ emissions are abated to reduce temperature increases to $2^{\circ} \mathrm{C}$ by 2100 , IPCC (2007) reports that such a scenario (B1 or A1T) is likely only if non-fossil energy sources dominate. Latest research shows that $\mathrm{CO}_{2}$ emissions continue to track at the high end of emission scenarios, with mean temperature increases of $4-5^{\circ} \mathrm{C}$ more likely by 2100 (Peters et al. 2013). The impacts on people and infrastructure will be considerable if there is no climate adaptation engineering to existing and new infrastructure. For example, the 2007 Stern Review found that rising sea levels will result in tens to hundreds of millions more people flooded each year with a warming of 3 or $4^{\circ} \mathrm{C}$, and climate change may reduce GDP by up to $3 \%$ by 2100 (or $\$ 2.1$ trillion per year based on 2011 GDP). The potential enormity of impacts of climate change leads some to posit that climate change can be a threat to national security (CNA 2007). On the other hand, higher temperatures in higher latitude regions such as Russia and Canada can be beneficial through higher agricultural yields, lower winter mortality, lower heating requirements, and a potential boost to tourism (Stern 2007). Lomborg (2009) assembled a group of international experts who found that climate change action ranked very low when compared with other hazard and risk-reducing measures, in this case the benefit-to-cost ratio for $\mathrm{CO}_{2}$ mitigation was only 0.9 (not costeffective), but increased to 2.9 for a mix of mitigation and adaptation strategies. This highlights the cost-effectiveness of adaptation when compared to $\mathrm{CO}_{2}$ mitigation.

The terms 'risk' and 'risk management' appear in the titles and text of many climate impact and adaptation studies (e.g. VG 2007, ATSE 2008, EEA 2012). However, these reports dwell on lists of vulnerabilities and consequences, and on qualitative measures such as risk ranking. There is seldom mention of probabilities, or quantitative measures of the likelihood or extent of losses. While useful for initial risk screening, intuitive and judgement-based risk assessments 
are of limited utility to complex decision-making since there are often a number of climate scenarios, adaptation options, limited funds and doubts about the cost-effectiveness of adaptation options. In this case, the decision-maker may still be uncertain about the best course of action. This led the Australian Academy of Technological Sciences and Engineering (ATSE) in 2008 to conclude that there "is a need to assess the impact of climate change on Australia's physical infrastructure on a regional basis by using risk assessment methods to provide overviews of the likelihood, consequence, risk and adaptation capacity of Australia's physical infrastructure" and that "information in the form of probability distributions is required for the capacity of infrastructure components after adaptation." For this reason, there is a need for sound system and probabilistic modelling that integrates the engineering performance of infrastructure with the latest developments in stochastic modelling, structural reliability, and decision theory.

The impact of climate change is discussed, with emphasis on increases in economic (loss) risks expected for existing infrastructure subject to climate-induced changes in wind field, floods and heatwaves, and increases in corrosion damage risks of steel and concrete infrastructure due to a changing climate. The risks are temporal and spatially dependent. Moreover, in an era where many governments and societies aim to reduce their carbon footprint, it is important that embodied energy be minimised in selecting, ranking, and optimising adaptation strategies. Changes to design and construction standards and retrofitting can reduce the vulnerability of new and existing infrastructure - but these can cost up to $40 \%$ of their original construction cost.

Sustainable construction and maintenance, and reducing energy consumption and $\mathrm{CO}_{2}$ emissions are undoubtedly the greatest challenge of the present century for those involved in infrastructure provision and life cycle maintenance planning/optimisation. The cement industry alone contributes $5-7 \%$ of the total global emissions (Worrell et al. 2001, Mehta 2004). Moreover, the construction sector is responsible for $17 \%$ of greenhouse emissions in India and between 8 $12 \%$ in Western Europe. Another concern is the need for new infrastructure in both developing and developed countries, which adds extra pressure towards the efficient use of construction materials in relation to their carbon footprint.

Risk-based decision support is described to assess the risks and economic viability of climate adaptation measures, especially on the aspect of life-cycle costs during their service - which includes embodied and operating energy costs. An important aspect is assessing when climate adaptation becomes economically viable, if adaptation can be deferred, and decision preferences for future costs and benefits (many of them intergenerational). Stochastic methods are used to model infrastructure performance, effectiveness of adaptation strategies, exposure, and costs. The concepts will be illustrated with state-of-the research of risk-based assessment of climate 
adaptation strategies including (i) resilience of interdependent infrastructure systems to floods, (ii) design of new houses in Queensland subject to tropical cyclones and severe storms, (iii) evaluation of effects of climate change and cost-effectiveness analysis of adaptation strategies in reinforced concrete structures subjected to chloride ingress, (iv) designing on- and offshore wind energy installations to allow for predicted evolutions in wind and wave loading, and (v) impact and adaptation to coastal inundation. This will pave the way for more efficient and resilient infrastructure, and help 'future proof' existing infrastructure to a changing climate.

\section{MODELLING WEATHER AND CLIMATE-RELATED HAZARDS IN CONDITIONS OF CLIMATE CHANGE}

The performance of infrastructure facilities such as bridges, buildings, dams, offshore structures, etc. is affected by environmental conditions, which are characterised by climate/weather variables (e.g. temperature, humidity, precipitation, wind speed). It may be affected by mean values of these variables as well as their variability, in particular extreme weather events (e.g. floods, storms, heat and cold waves). In the following, current approaches to modelling weather variables and extreme weather events in conditions of climate change are briefly described.

\subsection{Climate Modelling}

Atmosphere-Ocean General Circulation Models (AOGCMs) are currently the main tool for climate change studies. AOGCMs are numerical models based on differential equations, which describe physical processes in the atmosphere and ocean (and usually land-surface and sea ice as well) and interactions between them. The differential equations are discretised over the globe using a three-dimensional grid with horizontal resolution between 125 and $400 \mathrm{~km}$. It has been demonstrated that AOGCMs are capable to reproduce past observed climate changes. This gives confidence in their ability to provide credible projections of future climate change, in particular at continental and large regional scales (Randall et al. 2007).

AOGCMs are very computationally demanding which limits their spatial resolution. As a result, they cannot consider explicitly many important small-scale processes (e.g., clouds, convection, land surface processes). The processes are taken into account via parameterisation, i.e., they are estimated from the model large-scale variables (e.g., temperature, humidity) based on semi-empirical relationships. This introduces major uncertainty in the models' projections. Low spatial resolution of AOGCMs creates difficulties in predicting extreme weather events since estimates of weather variables are averaged over a grid cell. For example, AOGCMs are able to 
simulate reasonably well extreme temperatures; however, they underestimate extreme precipitation predicting more days of light rainfall and reduced magnitude of its extremes compared with point observations. The climate models provide sufficiently reliable estimates for weather events with dimensions of four grid cells and above which means that phenomena smaller than at least $500 \mathrm{~km}$ (e.g., tropical cyclones, tornados) cannot be represented well by AOGCMs (Feser et al. 2011). Thus, to assess impacts of climate change on infrastructure the resolution of AOGCMs is, in many cases, insufficient.

Generating climate data below the grid scale of AOGCMs (or shorter GCMs) is called downscaling. There are two main methods of downscaling, dynamical and statistical (e.g., Murphy 1999). Dynamical downscaling is achieved by using regional climate models (RCMs), which have a higher resolution than GCMs and nested within them, i.e., outcomes of GCM runs provide boundary conditions for a RCM that ensures dynamical consistency between the different scale models. A typical RCM can cover an area $5000 \mathrm{~km} \times 5000 \mathrm{~km}$ (e.g., western Europe) and has a horizontal resolution $25-50 \mathrm{~km}$ so it can account more accurately for such features as surface topography and land use. The spatial resolution of RCMs means that they are able to describe reasonably accurately weather events with dimensions of about $100 \mathrm{~km}$ or larger. This may still be insufficient to realistically model local extreme weather events like tornadoes or extreme rainfall.

Statistical downscaling is referred to a group of methods based on establishing statistical relationships between observed large-scale climate variables (i.e., at the scale of GCMs) and those at a local scale. The relationships can then be applied to GCM (or RCM) outputs to obtain the local variables. One of the methods of statistical downscaling is weather generators, which are intended to provide high spatial (e.g., 5-km gridded) and temporal (daily or even hourly) resolution time series of internally consistent weather variables. Such data may be very useful in various applications related to the infrastructure adaptation to climate change, especially when effects of more than one weather variable need to be considered.

Weather generators are usually based on stochastic precipitation models, i.e., precipitation is treated as the primary weather variable which is generated first, while other weather variables (e.g., temperature, humidity, wind speed) are determined by regression relationships with precipitation and values of the variables on the previous day (e.g., Kilsby et al. 2007). There are a number of stochastic precipitation models that have been employed in weather generators, including simple models using a Markov chain for occurrence and an exponential or gamma distribution for quantity (e.g., Chen et al. 2010) and more advanced models based on Poisson cluster processes, which represent precipitation occurrence and quantity as a single continuous 
process and are able to simulate the observed temporal clustering nature of rainfall (e.g., Burton et al. 2010). The Neyman-Scott Rectangular Process model, which belongs to the latter group, is used, for example, in the UKCP09 weather generator (Jones et al. 2010). One of major shortcomings and sources of uncertainty associated with weather generators (as well as other methods based on statistical downscaling) comes from a founding unverifiable assumption that relationships between large-scale climate variables and weather variables at a local scale remain unchanged under future climate change.

There are numerous sources of uncertainty associated with future climate modelling, which can be broadly divided into the following groups:

(i) Natural climate variability, i.e., caused by natural factors (e.g., variations in solar radiation, aerosol loading due to major volcanic eruption)

(ii) Uncertainty in future emission scenarios

(iii) Modelling uncertainty (e.g., parameterisation).

The main approach to quantification of the uncertainties is based on ensemble simulations, which can be generated by (IPCC 2012): (i) obtaining data from a range of GCMs (or RCMs) (multi-model ensembles) to account for the model differences, which reflect incomplete understanding of underlying physical processes forming the climate system (i.e., modelling uncertainty); (ii) generating data with different initial conditions (intra-model ensembles) to account for uncertainties due to natural climate variability; and (iii) varying internal model parameters within plausible ranges (perturbed or stochastic physics ensembles) also to account for modelling uncertainty. Uncertainties associated with future emission scenarios are usually not quantified and future climate projections are produced separately for individual scenarios. The UK Climate Projections (UKCP09) can serve as an example of the quantification of uncertainties associated with future climate modelling and producing probabilistic climate projections (Murphy et al. 2009). The multi-model ensemble in UKCP09 includes 12 different climate models that were considered in international model comparisons. Single climate projections provided by these models are then combined with the perturbed physics ensemble, which consists of 280 variants of the Met Office Hadley Centre (UK) climate model HadSM3, within a Bayesian statistical framework, to produce the UKCP09 probabilistic climate projections.

\subsection{Modelling Extreme Events Under Non-Stationary Conditions}

Extreme weather events (e.g., wind storms, floods, heatwaves) pose a major threat to infrastructure. As a result of climate change, their frequency and intensity may increase and infrastructure needs to be adapted accordingly. To this purpose, it is essential to have models of extreme 
events, which are able to take into account future trends due to climate change, i.e., nonstationarity of relevant stochastic processes. The main concepts of non-stationary extreme value analysis have been considered by Coles (2001). Methods for modelling extremes of nonstationary processes are similar to those of stationary ones and include: (i) the generalised extreme value (GEV) distribution for block maxima; (ii) the generalised Pareto distribution (GPD) for threshold exceedances; and (iii) a point process characterisations of extremes (PPE).

\subsubsection{Generalised Extreme Value (GEV) Distribution for Block Maxima}

Let $X$ be a random variable (or process), which represents a weather variable or event (e.g., average daily temperature, hourly amount of precipitation), and $X_{i}^{\prime}$ 's $(i=1, \ldots, n)$ observations of this process at different points in time, which can be treated as independent and identically distributed random variables. Denote the maximum of these random variables as $M_{n}$, i.e., $M_{n}=\max \left\{X_{1}, \ldots, X_{n}\right\}$. It can be proven that if there exists a sequence of constants $a_{n}>0$ and $b_{n}$ such that $\operatorname{Pr}\left[\left(M_{n}-b_{n}\right) / a_{n} \leq z\right] \rightarrow G(z)$ as $n \rightarrow \infty$, where $G$ is a non-degenerate distribution function, the latter has the following form

$$
G(z)=\exp \left\{-\left[1+\xi\left(\frac{z-\mu}{\sigma}\right)\right]_{+}^{-1 / \xi}\right\}
$$

where $a_{+}=\max \{0, a\}, \mu$ is a location parameter, $\sigma>0$ a scale parameter, and $\xi$ a shape parameter. This distribution is called the generalised extreme value (GEV) distribution and Eqn. (1) represents its classical formulation, when the underlying process is stationary. In order to estimate the parameters of this distribution, observations are usually divided into blocks of a sufficiently long length $n$, out of which the block maxima are selected and the GEV distribution is then fitted to them.

To take into account effects of climate change, processes causing extreme weather events need to be treated as non-stationary. Thus, a random variable representing an extreme weather event should be time variant and will be denoted as $Z_{t}$, where $t$ is time (e.g., in years). In the context of the GEV distribution of $Z_{t}$ this means that its parameters become time variant as well. If to denote the GEV distribution given by Eqn. (1) as $G(\mu, \sigma, \xi)$ the distribution of $Z_{t}$ can then be expressed as

$$
\mathrm{Z}_{\mathrm{t}} \sim \mathrm{G}(\mu(\mathrm{t}), \sigma(\mathrm{t}), \xi(\mathrm{t}))
$$

The distribution parameters in Eqn. (2) are functions of time, which should reflect future trends in the magnitude and frequency of the corresponding extreme event. For example, changes in 
the location parameter $\mu$ can be described by a linear or parabolic function, while for the scale parameter $\sigma$ it may be an exponential function to ensure that $\sigma$ will remain positive; however, it may be very difficult to select a smooth function of time for $\xi$ (Coles 2001). Parameters of these functions can be estimated by statistical downscaling. Non-stationary statistical approaches based on the GEV distribution have been employed, e.g., to model storm surge heights (Mudersbach and Jensen 2010) and annual extreme minimum air temperatures (Blain 2011).

\subsubsection{Generalised Pareto Distribution (GPD) for Threshold Exceedance}

The use of the GEV distribution along with the block maxima approach for the parameter estimation results in the loss of a large amount of data since out of each block only one data point, its maximum, is used. A more efficient approach in terms of the data use is to treat all observations $X_{i}$ above a high threshold $u$ as extreme events. It then can be proved that the distribution function of $Y=(X-u)$ conditional on $X>u$ asymptotically approaches (as $u$ increases) the generalised Pareto distribution (GPD) given by the following formula (e.g., Coles 2001)

$$
\mathrm{H}(\mathrm{y})=1-\left(1+\xi \frac{\mathrm{y}}{\psi}\right)_{+}^{-1 / \xi}
$$

where $\psi>0$ is a scale parameter, and $\xi$ a shape parameter. The GPD and the GEV distribution based on the same series of observations are related in the sense that $\psi=\sigma+\xi(u-\mu)$ and the shape parameter $\xi$ of the GPD is theoretically equal to that of the corresponding GEV distribution. In practice, changing the block size $n$ affects the values of the GEV distribution parameters, while the parameters of the corresponding GPD remain unchanged.

In the case of non-stationarity of a weather variable/event under consideration, the parameters of the GPD may be treated as functions of time, i.e., $\psi(t)$ and $\xi(t)$, in particular it may be appropriate to choose time-variant thresholds $u(t)$ (Coles 2001). Statistical approaches based on the GDP have been used to analyse, e.g., temperature extremes (Lucio et al. 2010) and extreme hydrological events such as drought and flood (Xu et al. 2010).

\subsubsection{Point Process Characterisation of Extremes (PPE)}

Another statistical approach that can be employed to model extreme weather events is based on combining the GEV and the GPD approaches to obtain a point process characterisation for extremes (PPE) (Heaton et al. 2011). This is achieved by introducing a bivariate process $(t, Z)$, where $Z$ is a random variable representing values of $X_{i}$ above a high threshold $u$, while a random variable $t$ is the time at which such events (i.e., $X_{i}>u$ ) occur. It can be shown that if the maxi- 
mum of $X_{i}$ 's follows the GEV distribution (Eqn. (3)) then the process $(t, Z)$ behaves as a nonhomogeneous Poisson process with intensity

$$
\lambda(\mathrm{t}, \mathrm{z})=\frac{1}{\sigma}\left[1+\xi\left(\frac{\mathrm{z}-\mu}{\sigma}\right)\right]_{+}^{-1 / \xi-1}
$$

where $\mu, \sigma$ and $\xi$ are the parameters of the corresponding GEV distribution. The main advantages of the PPE approach are that the parameters of the GEV distribution are retained (and can be treated as time variant), not only block maxima but other observations above the threshold $u$ are taken into account, while at the same time parameter estimates do not depend on $u$ as in the GPD approach. Examples illustrating the use of the PPE approach in the context of statistical analysis and modelling of extreme weather events can be found in Coles (2001).

\section{IMPACTS OF CLIMATE CHANGE}

\subsection{Corrosion and Material Degradation}

One of the consequences of an increase in $\mathrm{CO}_{2}$ concentration and temperature, and changes in relative humidity and rainfall, is an acceleration of deterioration (corrosion) processes that consequently affect the durability, safety, and serviceability of existing concrete, steel and timber infrastructure. In particular, many existing structures, for which the design has not taken into account the effect of changing climate, are likely to suffer from decreased durability and incur more damage and increased life cycle maintenance costs. The annual cost of corrosion worldwide is estimated to exceed $\$ 1.8$ trillion, which translates to $3 \%$ to $4 \%$ of the Gross Domestic Product (GDP) of industrialized countries (Schmitt 2009). Since the direct and indirect costs of corrosion are immense, a climate-change induced acceleration of the corrosion process by only a few percent can result in increased maintenance and repair costs of hundreds of billions of dollars annually.

Until recently all corrosion research assumed constant average climatic conditions for the development of models. This is still the case but some efforts have been made to consider the effect of changes in the parameters involved. For example, for atmospheric corrosion models $\mathrm{CO}_{2}$ levels, time of wetness, temperature, humidity, etc. typically are modelled as stationary variables. An increase in temperature will increase the rate of infiltration of deleterious substances (increased material diffusivity) and increase the corrosion rate of steel. For example, short-term corrosion rates for steel reinforcement increase by up to $15 \%$ if the atmospheric temperature in- 
creases by only $2^{\circ} \mathrm{C}$ (Stewart et al. 2012a). The A1FI emission scenario predicts $\mathrm{CO}_{2}$ concentrations increasing by more than $160 \%$ to $1,000 \mathrm{ppm}$ by 2100 , and this will increase carbonation depths of concrete by up to $36 \%$ (Stewart et al. 2012a). An increase in relative humidity may increase the 'time of wetness' which will increase short-term atmospheric corrosion rates of steel (Nguyen et al. 2013). Changes in temperature and rainfall can increase fungi decay of wood-based materials by up to $10 \%$ by 2080 , and timber strength decrease by almost $25 \%$ after 50 years (Wang and Wang 2012).

\subsection{Frequency and Intensity of Climate Hazards}

Climate change may involve sea level rise, temperature increase as well as changes in weather patterns such as wind and rainfall (IPCC 2007). While the general trend in change of climate variability has yet been clearly known, it is in agreement that the increase in the mean value of climate variables along their long term trend raises the likelihood of more extreme events. As shown in Figure 1 the increase in average temperature over time may increase the probability of temperature exceeding a specified threshold, which defines an extreme weather and could be related to those such as public health, energy consumption, and serviceability of infrastructure. In fact, an increase in the average value of climate variables may also push up the intensity of the weather event with the same exceedance probability or return period.

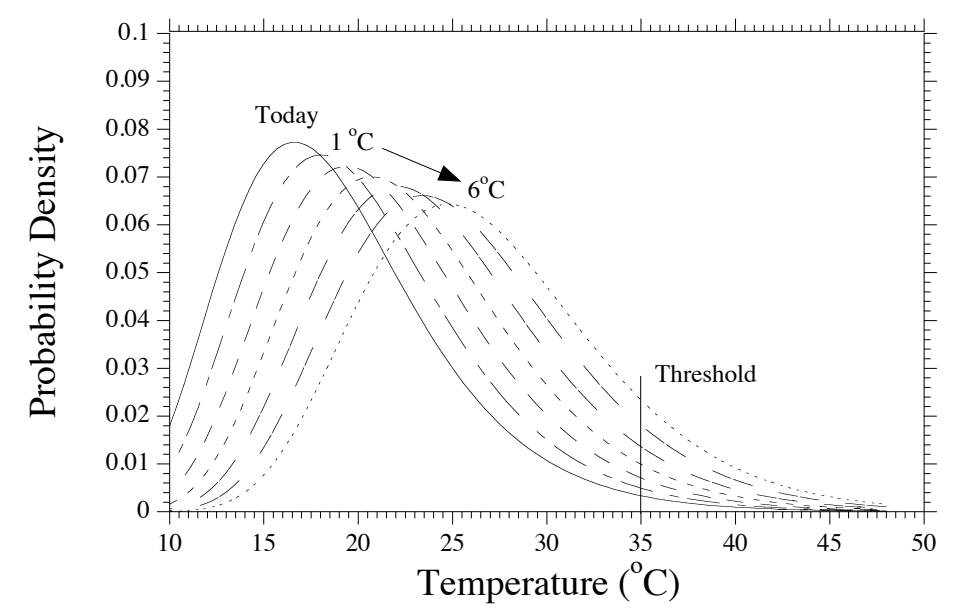

Figure 1: Increase in average temperature and probability of exceeding a defined threshold.

This becomes more evident for the storm tide described in relation to its return period, as shown in Figure 2. A sea level rise may increase the intensity of storm tide at the same return period, leading to a reduced return period or more frequent occurrence in the future for the same level 
of storm tides. In another words, it is likely that we would incur more frequent or more intense costal inundation if we take into account sea level rise in the future.

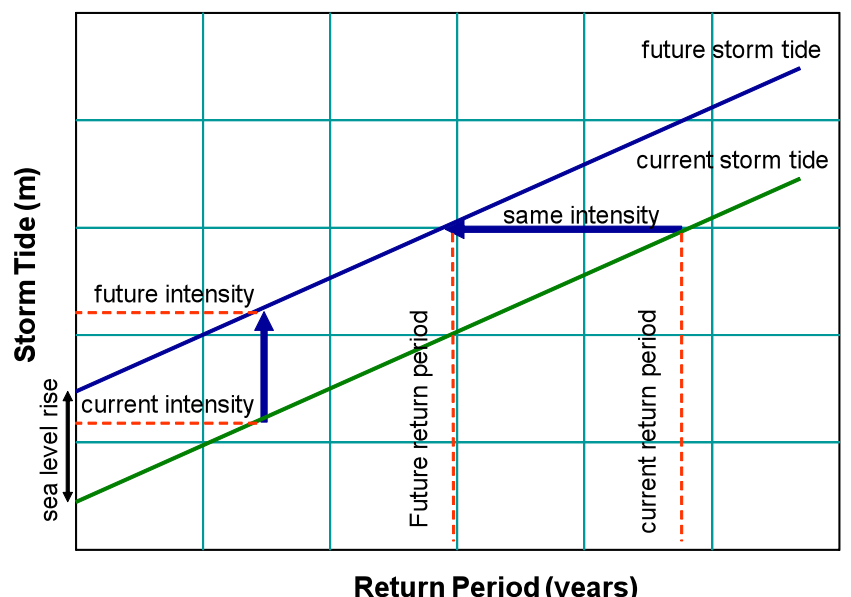

Figure 2: Effect of increasing hazard intensity on return periods.

Climate change leads to the warming of tropical sea surface temperature that is considered to be related to tropical cyclone activities (Knutson et al. 2010), and it may cause an increase in the frequency of storms and cyclones with high-intensity (Mendelsohn et al. 2012). However, there are many uncertainties around global warming on tropical cyclones and hurricanes. A lack of a reliable and consistent dataset and simulation platform of tropical cyclones over sufficient long periods of time and spatial space is a central issue to ascertain the existence of climate change impact on tropical cyclones. Having said that, it is valid to take the precautionary approach to consider the likely change in extreme winds in the design of engineering structures.

\subsection{Sustainability and Embodied Energy Requirements for Maintenance Strategies}

The World Commission on Environment and Development (1987) defines sustainable development as: "development that meets the needs of the present without compromising the ability of future generations to meet their own needs". According to Struble and Godfrey (2004), there are three components of sustainability: environment, economy and society. To meet its goal, sustainable development must provide a balance between these components (Sánchez-Silva and Rosowsky 2008). The main challenge in sustainable management of existing structures is to formulate maintenance strategies and/or adaptation measures technically and economically feasible, that reduce the environmental impact and that ensure optimal levels of serviceability and safety during the operational life. Recent advances in management aim to improve the performance of repair strategies by optimizing agency costs (Frangopol 2010). However, multiple re- 
quirements imposed nowadays by environmental and societal constraints undergo sustainable maintenance optimisation into a major challenge to designers, owners and users of structures. Infrastructure investment/development will not only bring a large amount of energy consumption directly but will also result in energy consumption indirectly through the use of materials which are energy intensive in their production, i.e. cement, steel, etc.

Not only is concrete an important source of $\mathrm{CO}_{2}$ emissions, but concrete has been recognised as the largest and most visible component of construction and demolition waste. According to estimates presented in the Environmental Resource Guide (American Institute of Architects, 1999), concrete accounts for up to $67 \%$ by weight of construction and demolition waste (53\% by volume), with only $5 \%$ currently recycled. Therefore, waste generation should also be included as a selection criterion for sustainable management.

Although alternative and more 'environmentally friendly' materials, such low $\mathrm{CO}_{2}$ cements, cement replacement materials with improved life-cycle durability characteristics, protective coatings etc. are now key areas of research and development (DuratiNet 2012), $\mathrm{CO}_{2}$ reductions can also be achieved by more efficient structural design and rehabilitation using more advanced assessment/planning techniques, including risk based approaches. This quantification of the possible $\mathrm{CO}_{2}$ savings has been made possible as a result of the compilation of data on the environmental impact of most construction materials (Hammond and Jones 2011).

Clearly, material and structural design optimisation, cost curtailment, embodied energy and carbon footprint minimisation are important parameters to be considered in infrastructure provision/maintenance. Considering embodied energy, for example, the embodied energy for in-situ concrete is approximately $0.7-1.1 \mathrm{GJ} / \mathrm{t}$ whereas for structural steel it is $23-35 \mathrm{GJ} / \mathrm{t}$ (McCaffrey et al. 2010). Significantly, newer and better materials are coming on stream with increased frequently. Estimates now count the number of engineering materials at more than 80,000 (Rashedi et al. 2012). Although these materials are meeting demand, there is still an opportunity to optimise material selection processes in infrastructure provision and/or maintenance. Green and recyclable materials are increasingly entering the market and their per unit cost is steadily declining due to advanced manufacturing and process technologies. This stands in clear contrast with the prices of the traditional materials such as concrete and steel which are simultaneously escalating due to inflationary onslaughts caused by developing markets.

Several life cycle analysis (LCA) techniques are readily available that can evaluate cradle to grave inventory and impact assessment of the entire infrastructure (McCaffrey et al. 2010). These LCA techniques lead to environmentally more sensible designs by engaging in a thorough material selection process exploring/identifying materials that can withstand short term as 
well as whole life structural demands from the combined perspectives of mass, performance, cost and environmental impact.

\section{RISK-BASED DECISION SUPPORT}

\subsection{Definition of Risk}

Risk (expected loss) for a system exposed to a climate hazard is

$$
\mathrm{E}(\mathrm{L})=\sum \operatorname{Pr}(\mathrm{C}) \operatorname{Pr}(\mathrm{H} \mid \mathrm{C}) \operatorname{Pr}(\mathrm{D} \mid \mathrm{H}) \operatorname{Pr}(\mathrm{L} \mid \mathrm{D}) \mathrm{L}
$$

where $\operatorname{Pr}(\mathrm{C})$ is the annual probability that a specific climate scenario will occur, $\operatorname{Pr}(\mathrm{H} \mid \mathrm{C})$ is the annual probability of a climate hazard (wind, heat, etc.) conditional on the climate, $\operatorname{Pr}(D \mid H)$ is the annual probability of infrastructure damage or other undesired effect conditional on the hazard (also known as vulnerability or fragility) for the baseline case of no extra protection (i.e. 'business as usual'), $\operatorname{Pr}(\mathrm{L} \mid \mathrm{D})$ is the conditional probability of a loss (economic loss, loss of life, etc.) given occurrence of the damage, and $\mathrm{L}$ is the loss or consequence if full damage occurs. The product $\operatorname{Pr}(\mathrm{D} \mid \mathrm{H}) \operatorname{Pr}(\mathrm{L} \mid \mathrm{D}) \mathrm{L}$ refers to the expected loss given the occurrence of the hazard. In some cases, 'damage' may equate to 'loss' and so a vulnerability function may be expressed as $\operatorname{Pr}(\mathrm{L} \mid \mathrm{H})$ which is equal to the product $\operatorname{Pr}(\mathrm{D} \mid \mathrm{H}) \operatorname{Pr}(\mathrm{L} \mid \mathrm{D})$. The summation sign in Eqn. (5) refer to the number of possible climate scenarios, hazards, damage levels and losses. If the loss refers to a monetary loss, then $\mathrm{E}(\mathrm{L})$ represents an economic risk.

If we modify Eqn. (5) where $\Delta \mathrm{R}$ is the reduction in risk caused by climate adaptation measures then expected loss after climate adaptation is

$$
\mathrm{E}_{\text {adapt }}(\mathrm{L})=\sum(1-\Delta \mathrm{R}) \mathrm{E}(\mathrm{L})-\Delta \mathrm{B}
$$

where $\Delta \mathrm{R}$ is the reduction in risk caused by climate adaptation (or other protective) measures, $\mathrm{E}(\mathrm{L})$ is the 'business as usual' expected loss (risk) given by Eqn. (5), and $\Delta \mathrm{B}$ is the co-benefit of adaptation such as reduced losses to other hazards, increased energy efficiency of new materials, etc. Climate adaptation measures should result in risk reduction $(\Delta \mathrm{R})$ that may arise from a combination of reduced likelihood of hazard, damage states, safety hazards and and/or people exposed to the safety hazard. For any climate adaptation measure the risk reduction $\Delta \mathrm{R}$ can vary from $0 \%$ to $100 \%$ (or even a negative number for an ill-suited adaptation measure).

The challenging aspect of risk-based decision theory is predicting values of $\operatorname{Pr}(\mathrm{C}), \operatorname{Pr}(\mathrm{H} \mid \mathrm{C})$, $\operatorname{Pr}(\mathrm{D} \mid \mathrm{H}), \operatorname{Pr}(\mathrm{L} \mid \mathrm{D})$ and $\Delta \mathrm{R}$. This information may be inferred from expert opinions, scenario 
analysis, and statistical analysis of prior performance data, as well as system and reliability modelling. Since there is uncertainty associated with such predictions, the use of probability distributions to describe mean, variance and distribution type is recommended.

There are significant challenges in characterising (in probabilistic terms) climate impact and adaptation in time and space. Quite rightly, there has been substantial research on climate variability as this will be the driver to climate impact. Future climate is projected by defining carbon emission scenarios in relation to changes in population, economy, technology, energy, land use and agriculture - a total of four scenario families, i.e., A1, A2, B1 and B2 are defined (IPCC 2000) and used in the IPCC's Third and Fourth Assessment Reports in 2001 and 2007, respectively. The A1 scenarios indicate very rapid economic growth, a global population that peaks in mid-century and declines thereafter, and the rapid introduction of new and more efficient technologies, as well as substantial reduction in regional differences in per capita income. Subcategories of A1 scenario include A1FI and A1B, which represent the energy in terms of fossil intensive and a balance across all sources, respectively. In addition, scenarios of $\mathrm{CO}_{2}$ stabilisation at $550 \mathrm{ppm}$ by 2150 were also introduced to consider the effect of policy intervention (Wigley 1996). The IPCC Fifth Assessment Report (AR5) to be released in 2014 will use Representative Concentration Pathways (RCPs) where RCP8.5, RCP6.0 and RCP4.5 are roughly equivalent to $\mathrm{A} 1 \mathrm{FI}, \mathrm{A} 1 \mathrm{~B}$, and $\mathrm{A} 1 \mathrm{~B}$ to $\mathrm{B} 1 \mathrm{CO}_{2}$ emissions, respectively.

To project spatially dependent future climates under different emission scenarios, various climate models have been developed (see Section 2.1). The IPCC suggests that it is necessary to use multiple AOGCMs to take into account the uncertainties of models in any impact assessment. The estimation of $\operatorname{Pr}(\mathrm{C})$ may be based on expert opinion about the likelihood of each emission scenario, and multiple AOGCMs may be used to infer the probabilistic characterisation of $\operatorname{Pr}(\mathrm{H} \mid \mathrm{C})$ for future climate projections including temperature and relative humidity.

Figure 3 describes the projection of $\mathrm{CO}_{2}$ concentrations from 1990 based on the Model for Assessment of Greenhouse-gas Induced Climate Change, known as MAGICC (Wigley et al. 1996), specifically related to A1FI, A1B and $550 \mathrm{ppm} \mathrm{CO}_{2}$ stabilisation scenarios. The coefficient of variation $(\mathrm{COV})$ of $\mathrm{CO}_{2}$ atmospheric concentrations is approximately 0.06 for projections at 2100 . The variability increases for projection of temperatures. For example, Figure 3 shows the projected median temperatures for the lowest and highest of nine GCM projections, for A1FI, A1B, $550 \mathrm{ppm}$ and Year 2000 emission scenarios for Sydney. The COV increases with time from 0.3 to a maximum value of approximately 0.4 to 0.5 for all emission scenarios. 


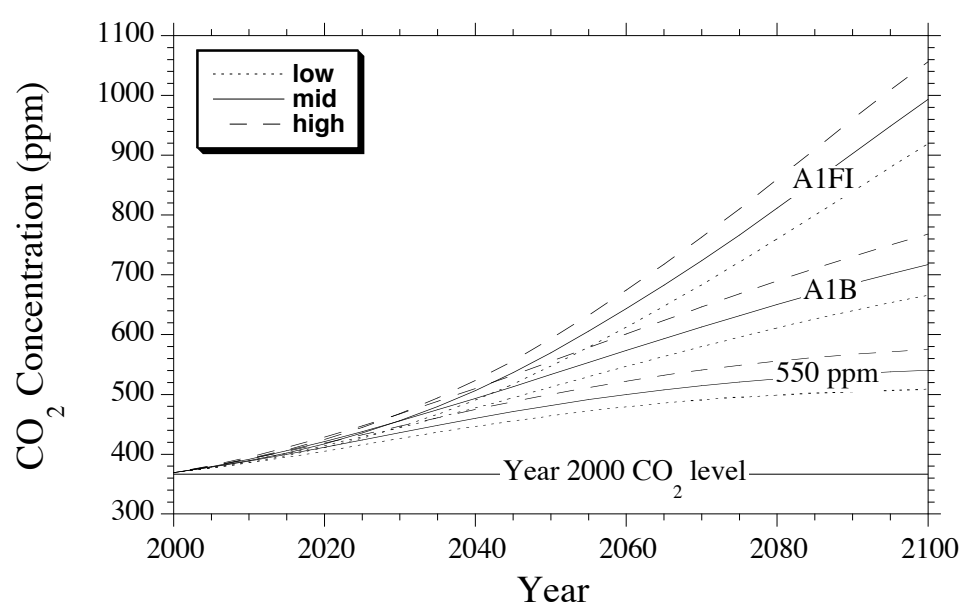

Figure 3: Projected low, mid and high estimates of $\mathrm{CO}_{2}$ concentrations.

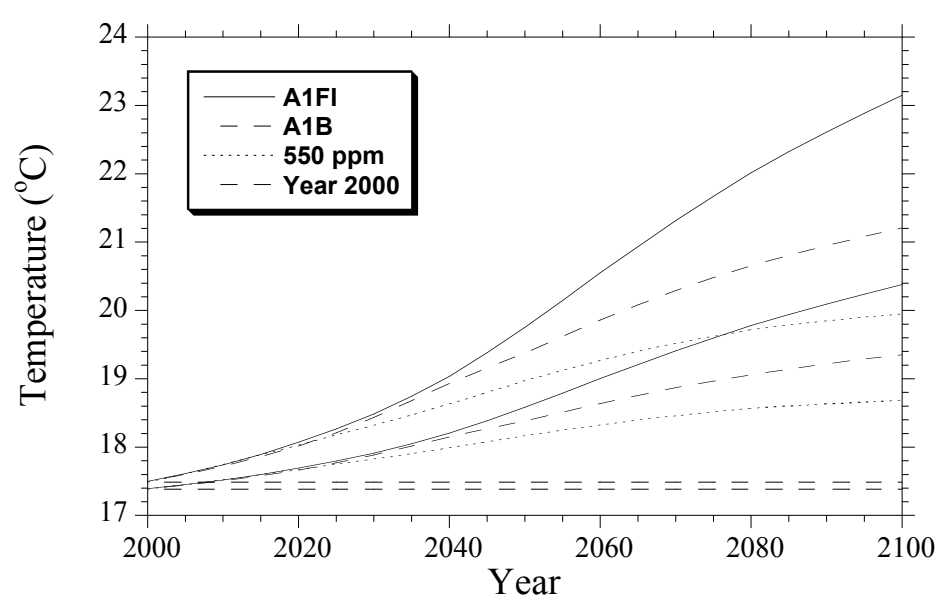

Figure 4: Projected median temperatures for the lowest and highest GCM predictions for the A1FI,

A1B, 550 ppm and year 2000 emission scenarios, for Sydney (Australia).

The stochastic modelling of infrastructure vulnerability (or fragility) is $\operatorname{Pr}(\mathrm{D} \mid \mathrm{H})$ and is the probability of damage conditional on the occurrence of a specific hazard:

$$
\operatorname{Pr}(\mathrm{D} \mid \mathrm{H})=\operatorname{Pr}(\mathrm{R}(\mathbf{X})-\mathrm{H}<0)
$$

where $R(\mathbf{X})$ is the function for resistance or capacity, $\mathbf{X}$ is the vector of all relevant variables that affect resistance, and $\mathrm{H}$ is the known hazard level. The performance functions can be expressed in terms of structural damage or other losses, and is derived from engineering models. As a structure ages the effect of deterioration and other time-dependent processes may lead to higher values of $\operatorname{Pr}(\mathrm{D} \mid \mathrm{H})$. For examples of fragility (or vulnerability) curves with respect to seismic risk see Ellingwood et al. (2007). 
Vulnerability modelling will require probabilistic information on materials, dimensions, model errors, deterioration and other input variables $(\mathbf{X})$ into engineering models which define the resistance function $R(\mathbf{X})$ - these variables vary in time and space. The reliability analysis of components is relatively straightforward, however, a more demanding challenge is reliability modelling of structural systems in time and space. This will require advanced simulation modelling to accurately track component and member performance and failure, load sharing, failure of other components/members due to load redistribution, and progression of structural failure leading to economic and other losses. The outcome is an estimate of the probability of damage conditional on a specific wind speed, flood level, temperature, or other hazard. Another challenge is that infrastructure, particularly houses, are very complex systems comprising of hundreds to thousands of components and members of differing materials. Poor detailing and workmanship issues contribute to most damage - so the engineering and stochastic models need to consider these variables - such as screw fasteners being spaced too far apart, or some not connected to purlins and battens, etc. These are more challenging to model stochastically than more conventional 'engineered' constructions such as bridges, towers, etc. where materials are more uniform, and workmanship subject to more quality control measures. Henderson and Ginger (2007) have conducted structural reliability analyses to assess the vulnerability $\operatorname{Pr}(\mathrm{D} \mid \mathrm{H})$ of timber-framed houses built in the 1960s and 1970s in northern parts of Australia subject to cyclonic wind speeds, see Figure 5. The roof envelope is clearly the most vulnerable structural component.

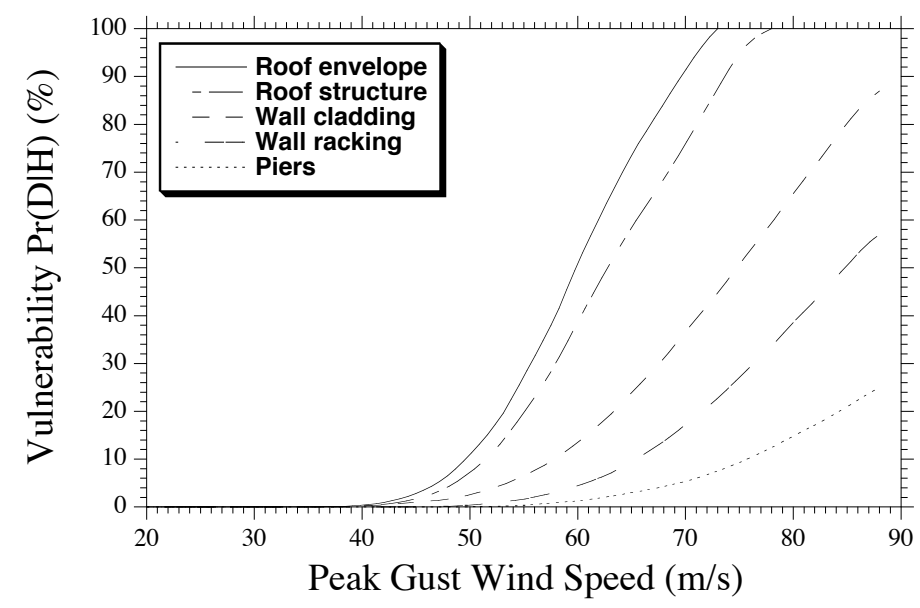

Figure 5: Vulnerability curves for timber-framed housing subject to cyclonic winds (adapted from Henderson and Ginger 2007).

The relationship between damage and loss often depends on the hazard and item of infrastructure being considered. For example, insurance or building performance data may be used to derive vulnerability models which are often expressed in terms of $\operatorname{Pr}(\mathrm{L} \mid \mathrm{H})$. Examples of vulnera- 
bility models for Australian houses subject to wind and floods are shown in Figures 6 and 7. In these cases, the hazard $\mathrm{H}$ is the water depth above the floor, and peak gust wind speed, respectively. For example, Figure 7 shows that houses designed to resist higher wind forces (such as Cairns in a cyclonic region Far North Queensland) have reduced vulnerability compared to houses in Brisbane which is a non-cyclonic region and so have less stringent design requirements.

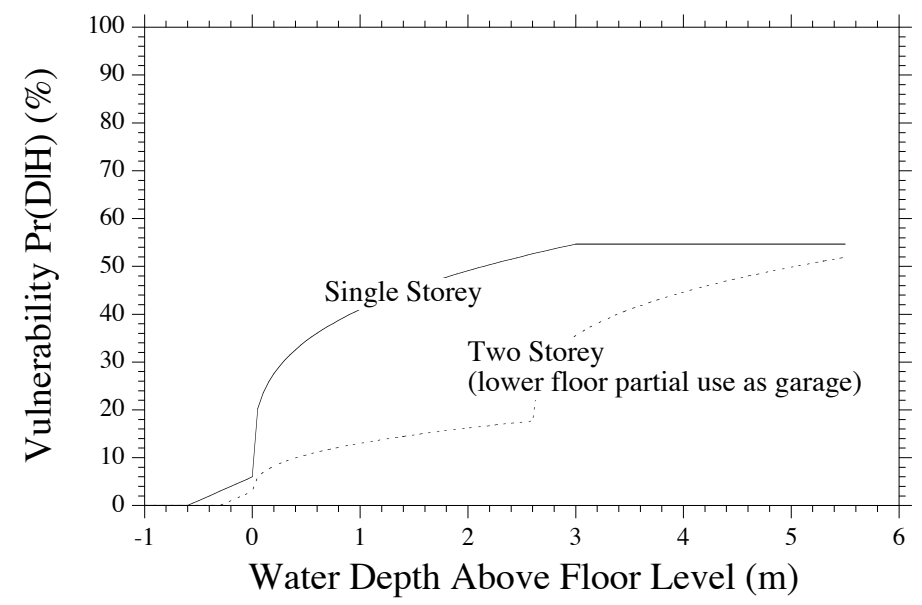

Figure 6: Flood vulnerability curves for residential construction in Brisbane (adapted from Mason et al. 2012).

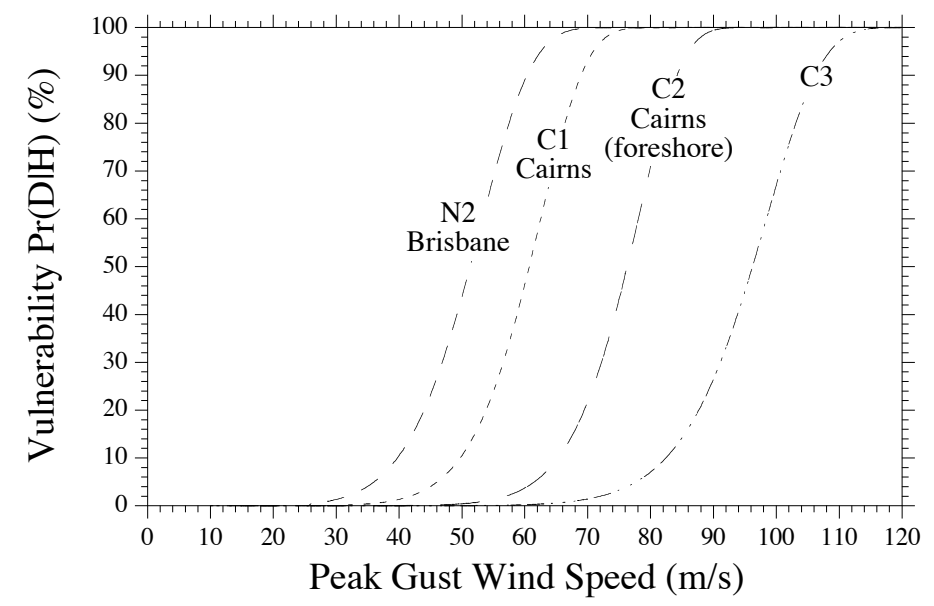

Figure 7: Wind vulnerability curves for residential construction in Queensland (adapted from Stewart et al. 2012b).

Exposure and loss data relates to direct and indirect loss or consequence due to location and extent of infrastructure damage, for existing exposure and future projections. Most existing studies consider direct losses related to building damage and contents losses. While these direct costs 
can be substantial, indirect losses caused by business interruption, clean-up, loss during reconstruction, extra demands on social services, and changes to demand and supply of intermediate consumption goods, etc. can also be significant (e.g. NAS 1999, Hallegatte 2008, Cavallo and Noy 2010). Moreover, post-disaster inflation can be up to $100 \%$ following a major natural disaster (e.g., Walker 2011).

Direct costs are the immediate consequences of the hazard - generally those associated with building damage and contents losses at the present price level (Hallegatte 2008). Most, if not all, direct loss models show damage and contents loss as a direct proportion (linear) of vulnerability $\operatorname{Pr}(\mathrm{D} \mid \mathrm{H})$.

Input-output (I-O) models are used to predict how a disaster (shock) on one or more sectors (e.g., construction, retail trade, utilities, manufacturing, professional and business service, educational services, health care, and government services) affect the demand and supply of intermediate consumption goods that cause a reduction in economic production (e.g. Greenberg et al. 2007, Hallegatte 2008). In other words, damage to capital stock will lower growth in the shortrun by reducing productivity and sector outputs. The I-O model is the most widely used tool for regional economic impact analysis, and its use for natural hazard loss estimations dates from the 1970s (Rose 2004). While the I-O model is not without its difficulties, it can provide an excellent starting point for assessing indirect losses due to extreme natural events.

Indirect losses were estimated for Hurricane Katrina using an adaptive regional I-O model where damage to houses was $\$ 20$ billion, contents $\$ 7$ billion, $\$ 17$ billion damage to government, and $\$ 63.5$ billion to the private sector - total damage to fixed capital was $\$ 107$ billion (Hallegatte 2008). The total indirect loss is $\$ 42$ billion or $39 \%$ of direct losses. Hallegatte (2008) estimates that indirect losses could exceed $100 \%$ of direct losses for a damaging event twice as bad as Hurricane Katrina. A Bureau of Transport Economics (BTE) assessment of direct and indirect costs for five natural disasters in Australia shows indirect costs of 9-40\% of direct losses for bushfire, cyclones and floods (BTE 2001).

There is often a high level of post-disaster inflation (or demand surge) of building costs in Australia (e.g., Walker 2011) which can lead to higher insurance and home owner losses. Walker (2011) estimates that the post-disaster inflation was close to $100 \%$ for Cyclone Tracy.

A probability of loss $\operatorname{Pr}(\mathrm{L} \mid \mathrm{D})$ and loss $\mathrm{L}$ needs to consider direct and indirect losses, but data is very limited to accurately quantify these trends. Figure 8 shows a typical loss function for wind vulnerability, where indirect losses start to accumulate for vulnerabilities that exceed $18 \%$, and total loss is twice the direct losses for a catastrophic event where $\operatorname{Pr}(\mathrm{D} \mid \mathrm{H})=100 \%$. 


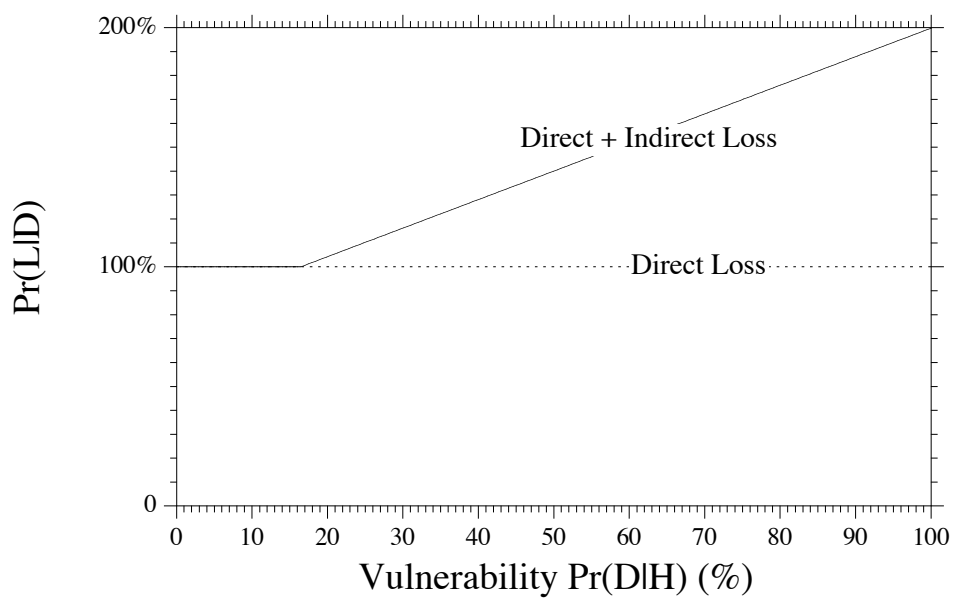

Figure 8: Direct and indirect costs as function of vulnerability (adapted from Stewart et al. 2012b).

Risk reduction $(\Delta R)$ may result from reduced vulnerability $\operatorname{Pr}(D \mid H), \operatorname{Pr}(L \mid D)$ or exposure (L). For instance, changes to planning may reduce the number of new properties built in a flood plain which will reduce $\mathrm{L}$, or more stringent design codes may reduce the vulnerability of new infrastructure. Systems and reliability modelling are essential tools to quantify the level of risk reduction, and the extent of risk reduction due to adaptation measures will depend on the hazard, location, and timing of adaptation.

The co-benefits of adaptation $(\Delta \mathrm{B})$ may include reduced embodied energy and reduced carbon footprint over the life cycle of the facility. This might consider the initial embodied energy associated with the dwelling including footings, structure and fit-out together with the recurrent embodied energy associated with refurbishment over the life cycle and the operational energy needed to operate a building.

Costs of adaptation, timing of adaptation, discount rates, future growth in infrastructure and spatial and time-dependent increase in climate hazards need to be included in any risk analysis. Of particular interest is uncertainty about the level of discount rates. Infrastructure Australia recommends that for a cost-benefit analysis of infrastructure projects the discount rate should be set at $4-10 \%$ to assess the sensitivity of discount rates (IA 2008). Discount rates are generally assumed constant with time. However, this may not be appropriate when considering intergenerational effects often associated with climate change policy decisions. For example, the U.K. Treasury recommends time-declining discount rates (e.g., Boardman et al. 2011) which places more emphasise on future benefits by reducing the discount rate. 


\subsection{Cost-Effectiveness of Adaptation Strategies}

Three criteria may be used to assess the cost-effectiveness of adaptation strategies:

1. Net Present Value (NPV)

2. Probability of cost-effectiveness or $\operatorname{Pr}(\mathrm{NPV}>0)$

3. Benefit-to-cost ratio or BCR

The 'benefit' of an adaptation measure is the reduction in damages associated with the adaptation strategy, and the 'cost' is the cost of the adaptation strategy. The net benefit or net present value (NPV) is equal to benefit minus the cost which is also equivalent to the present value or life-cycle cost of an adaptation strategy (sum of damage and adaptation costs) minus the 'business as usual' or 'do nothing' present value. The decision problem is to maximise the net present value

$$
\mathrm{NPV}=\sum \mathrm{E}(\mathrm{L}) \Delta \mathrm{R}+\Delta \mathrm{B}-\mathrm{C}_{\text {adapt }}
$$

where $\mathrm{C}_{\text {adapt }}$ is the cost of adaptation measures including opportunity costs that reduces risk by $\Delta \mathrm{R}, \Delta \mathrm{B}$ is the co-benefit from the adaptation measure not directly related to mitigating vulnerability or hazard (such as improved energy efficiency, reduced embodied energy, etc.), and E(L) is the 'business as usual' expected loss (risk) given by Eqn. (5). The benefit-to-cost ratio is:

$$
\mathrm{BCR}=\frac{\sum \mathrm{E}(\mathrm{L}) \Delta \mathrm{R}+\Delta \mathrm{B}}{\mathrm{C}_{\text {adapt }}}
$$

If parameters $\operatorname{Pr}(\mathrm{C}), \operatorname{Pr}(\mathrm{H} \mid \mathrm{C}), \operatorname{Pr}(\mathrm{D} \mid \mathrm{H}), \operatorname{Pr}(\mathrm{L} \mid \mathrm{D}) \mathrm{L}, \Delta \mathrm{R}, \Delta \mathrm{B}$ and/or $\mathrm{C}_{\text {adapt }}$ are random variables then the output of the analysis (NPV or BCR) are also variable. This allows confidence bounds of NPV or BCR to be calculated, as well as the probability that an adaptation measure is costeffective at time $\mathrm{T}$ denoted herein as $\operatorname{Pr}(\mathrm{NPV}>0)$. If $\mathrm{NPV}>0$ or $\mathrm{BCR}>1$ then there is a net benefit and so the adaptation measure is cost-effective. Other notations and formulae can be used to provide optimal adaptation, but ultimately these also mostly rely on maximising NPV (e.g., Hall et al. 2012).

If the probability that a specific climate scenario will occur $\operatorname{Pr}(\mathrm{C})$ is too unreliable, then a decision analysis based on scenario analysis where climate scenario probability is decoupled from Eqn. (5) provides an alternative decision-making criteria based on expected costs. The above equations can be generalised for any time period, discounting of future costs and more detailed time-dependent cost and damage consequences. If the loss refers to the fatality of an individual, 
then $\mathrm{E}(\mathrm{L})$ represents an individual annual fatality risk which can be compared with appropriate societal risk acceptance criteria (Stewart and Melchers 1997).

Governments and their regulatory agencies normally exhibit risk-neutral attitudes in their decision-making as described by Eqns. (8-9) above. This is confirmed by the U.S. Office of Management and Budget (OMB) which specifically states that "the standard criterion for deciding whether a government program can be justified on economic principles is net present value - the discounted monetized value of expected net benefits (i.e., benefits minus costs)" and that "expected values (an unbiased estimate) is the appropriate estimate for use" (OMB 1992), and also by many practitioners and researchers (e.g., Sunstein 2002, Faber and Stewart 2003, Ellingwood 2006). This entails using mean or average estimates for risk and cost-benefit calculations, and not worst-case or pessimistic estimates. Paté-Cornell (2002) elaborates on this point by stating "if risk ranking is recognized as a practical necessity and if resource limitations are acknowledged, the maximum overall safety is obtained by ranking the risks using the means of the risk results (i.e., expected value of losses)."

This type of "rational" approach to risky decision making is challenging to governments and their agencies which might have other priorities and political concerns. Hardaker et al. (2009) note that "policy-making is a risky business", and that "Regardless of the varied desires and political pressures, we believe that it is the responsibility of analysts forcefully to advocate rational decision methods in public policy-making, especially for those with high risk. We believe that more systematic analysis of risky policy decisions is obviously desirable." If rational approaches to public policy making are not utilised, then politically driven processes "may lead to raising unnecessary fears, wasting scarce resources, or ignoring important problems." (PatéCornell 2002). Probability neglect is a form of risk aversion as decision-makers are clearly averse to events of large magnitude irrespective of the probability of it actually occurring. Utility theory can be used if the decision maker wishes to explicitly factor risk aversion or proneness into the decision process (e.g. Jordaan 2005, Stewart et al. 2011).

It is important to note that the issue of risk aversion is not a new one, but has been well researched and documented for politically sensitive and controversial decisions associated with nuclear power safety, aviation safety, pharmaceutical benefits scheme, environmental pollution, etc. In these cases, risk acceptance criteria has been developed based on annual fatality risks and net benefit analysis using expected (mean) values. In principle, decisions related to climate adaptation measures should be made with similar risk-based methodologies. 


\subsection{Resilience of Interdependent Infrastructure Systems to Floods}

One of the most vivid examples of the potential danger of weather-related hazards to the UK infrastructure occurred in the summer of 2007 when floods from extreme rainfall caused closures of electricity substations and water treatment plants, and severed arterial roads critical to the delivery of public services (Pitt 2008). In particular, the floods caused a shutdown of the Castlemeads primary electricity substation and the Mythe water treatment works in Gloucestershire. The latter left 350,000 people without water supply for 9 days and without drinking water for 17 days.

It is essential to develop efficient strategies for improving the resilience of essential infrastructure systems that will ensure their continuous and reliable performance in the future, both at national and local levels. Simulation of the performance of such systems using numerical models may be of major assistance in developing such strategies. In order to provide a realistic prediction of the performance of various infrastructure systems, especially when they are subject to weather-related hazards, it is important to account for their interdependencies, i.e., when failure in one system causes severe disruptions and failures in other systems. It is also important to take into account uncertainties associated with the prediction of hazard effects and with the performance of infrastructure assets subject to these effects.

A model to simulate the performance of interdependent infrastructure systems under normal and hazardous conditions at the local scale has been developed by Holden et al. (2013). The model is based on an extended net flow approach, in which infrastructure systems are considered as a network of nodes connected by directed edges. The nodes represent physical infrastructure assets (e.g., electricity substations, water treatment works, water pumping stations, hospitals, residential areas) associated with production, consumption, transhipment and storage of resources (e.g., water, wastewater, electricity, fuel), which are referred to as commodities. The edges model the flow of commodities between the nodes and may represent, e.g., power transmission and distribution lines, water and wastewater pipelines, roads, etc. The model allows optimization of infrastructure performance by minimizing the total operational cost - i.e., the sum of costs associated with production, storage and flow of commodities. Since the model has been developed to simulate the infrastructure performance at the local scale it has higher node resolution compared to typical models of infrastructure systems at the national level, e.g., it has capabilities to account for local infrastructure components such as storage facilities and emergency generators. In order to simulate the operation of damaged infrastructure it may be 
necessary to deal with unsatisfied demand. For this purpose, a variable representing unsatisfied demand (or shortage) is introduced along with the corresponding cost (or penalty).

The following example illustrates the application of the model to examine the performance of two interdependent infrastructure systems (energy and water) at the local level during a flood event (see Figure 9). The energy system includes four electricity substations - a national grid substation (node 2: maximum capacity is $20 \mathrm{MWh} /$ day) and three distribution substations (nodes 4 and 7: maximum capacity $5 \mathrm{MWh} /$ day; node 5 : maximum capacity $10 \mathrm{MWh} /$ day). The water system includes a water treatment plant (node 1 : maximum capacity $1000 \mathrm{~m}^{3} /$ day), a water tower (node 3: maximum storage capacity $550 \mathrm{~m}^{3}$ ) and a water pumping station (node 6 : maximum capacity $200 \mathrm{~m}^{3} /$ day); $1 \mathrm{kWh}$ is required to pump $7.5 \mathrm{~m}^{3}$ of water. There are three nodes representing consumers: a hospital (node 8), a care home and surrounding residential area (node 9) and a residential area (node 10); their daily demands for electricity and water are given in Table 1. Two options are considered: (i) without emergency generators; (ii) with emergency generators at the nodes 3, 6 and 8 . Each generator has a power of $12 \mathrm{~kW}$, a storage tank for 100 1 of fuel, and can produce $3 \mathrm{kWh}$ per litre of consumed diesel.

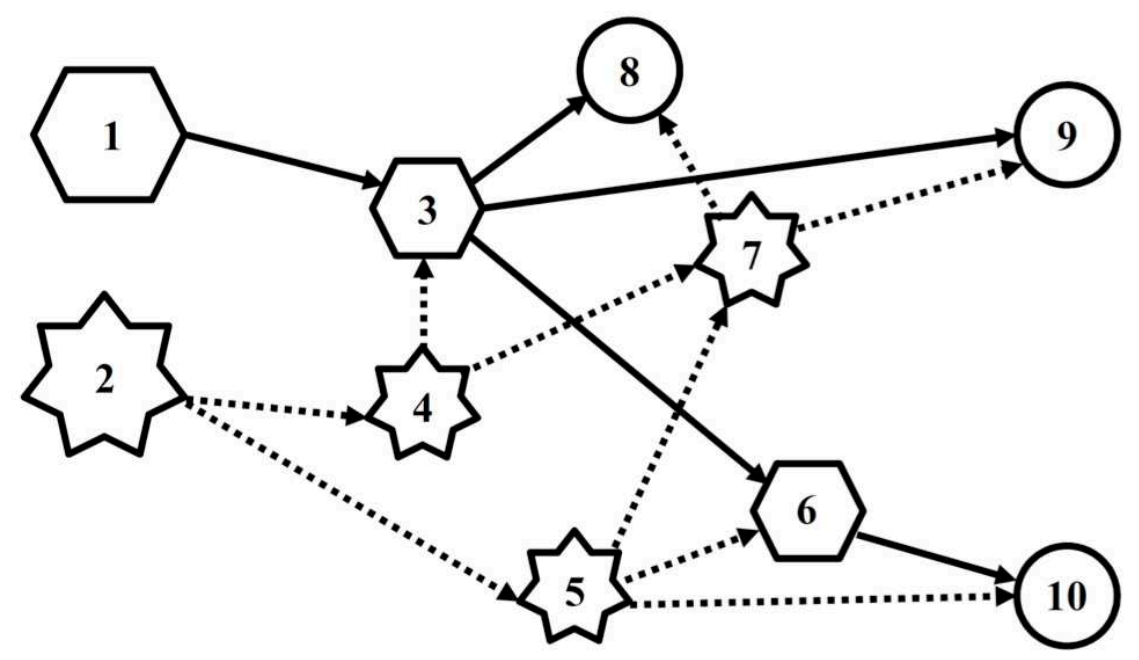

Figure 9: Network model of considered infrastructure (solid lines - water pipelines, dashed lines - distribution power lines).

Table. 1: Electricity and water demands by consumers (nodes 8-10).

\begin{tabular}{lcc}
\hline Consumer & \multicolumn{2}{c}{ Daily demands } \\
\hline & Electricity (MWh/day) & Water $\left(\mathrm{m}^{3} /\right.$ day) \\
\cline { 2 - 3 } 8 - Hospital & 1.3 & 35 \\
9 - Care home \& residential area & 3.1 & 75 \\
$10-$ Residential area & 6.0 & 165 \\
\hline
\end{tabular}


Flood modelling is not explicitly considered in this example. It is merely assumed that the probabilities of shutdown (i.e., failure) of the distribution electricity substations due to a particular flood (i.e., hazard), i.e. $\operatorname{Pr}(\mathrm{D} \mid \mathrm{H})$, have been estimated as: 0.6 for the node $4,0.3$ for the node 5 , and 0.1 for the node 7 . The infrastructure network will function in a partially damaged condition until the electricity substations will return to operation, which may take several days. The example examines what happens with the supply of electricity and water to the consumers when it takes up to 6 days to restore these substations. The analysis is carried out using a daily time step. The costs of flow, storage, production and shortage do not represent actual costs in this example and are assigned to ensure that the commodities are distributed between the consumers as intended. The hospital has the highest priority in receiving required commodities, followed by the care home and then the residential area. The costs of shortages of water and electricity for these consumers are set accordingly, i.e., the highest costs for the hospital, a lower costs for the care home and the lowest ones for the residential area.
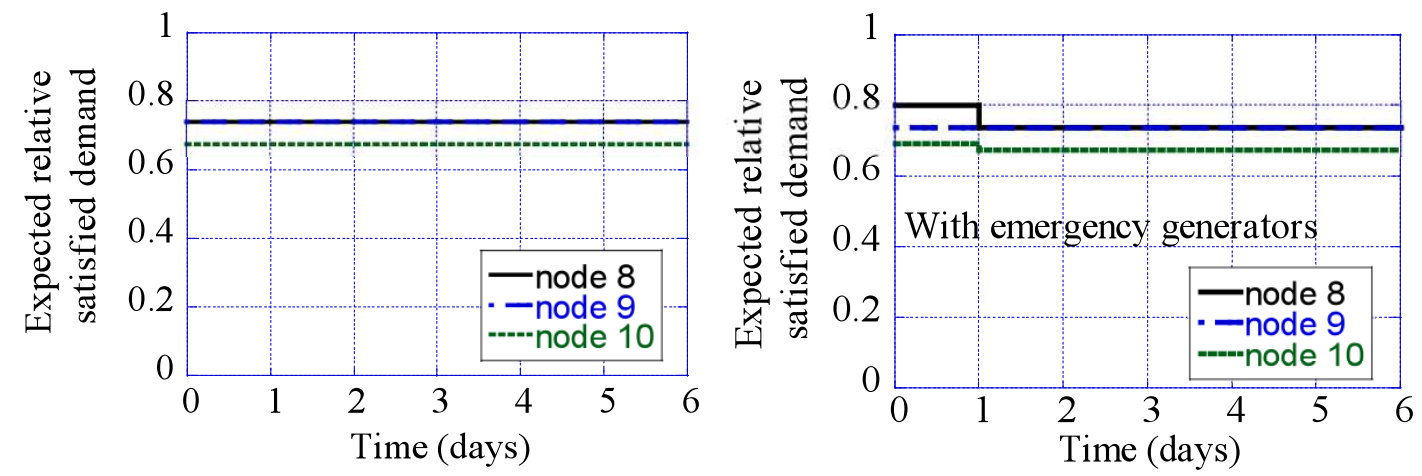

(a) electricity
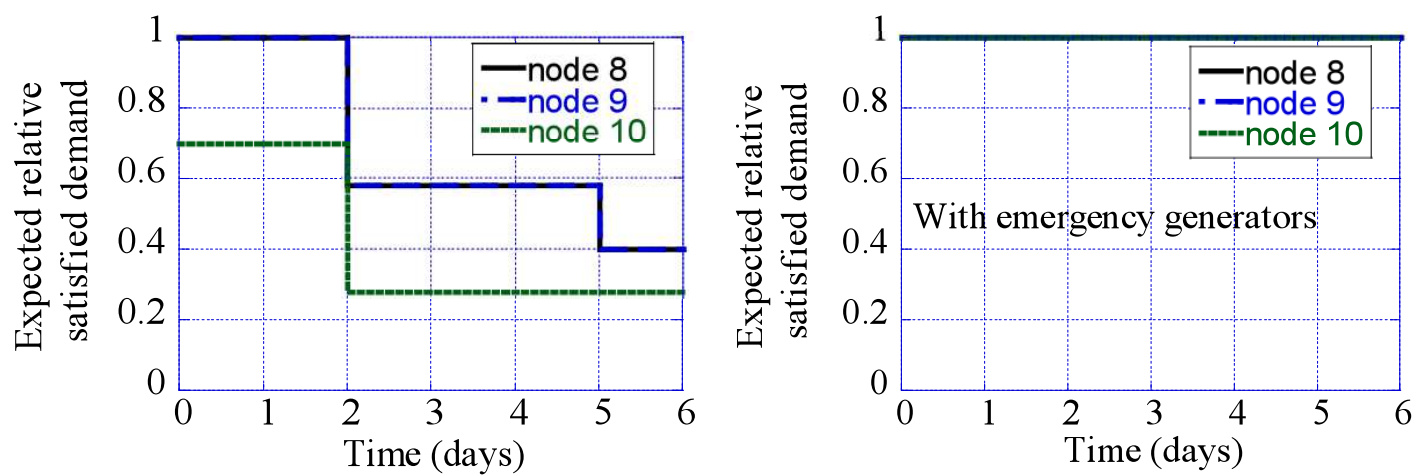

b) water

Figure 10: Expected relative satisfied demand for commodities.

There are a number of parameters characterising the performance of the infrastructure network that can be estimated. However, results for only one parameter - the expected relative satisfied 
demand, are presented herein in Figure 10. As can be seen, the emergency generators are very useful in preventing disruptions in water supply. It has further been checked that with the relatively small amount of stored fuel they are capable to ensure continuous supply of water to the consumers for up to 11 days when the electricity substations are not functioning. The model can be used to examine the performance of much more complicated infrastructure networks, with higher temporal resolution (e.g., hourly) and also enables to treat, if necessary, parameters of the network (e.g., demands, production and/or flow capacities) as continuous random variables.

\subsection{Strengthening Housing in Queensland Against Extreme Wind}

Cyclone Larry caused over $\$ 1$ billion in damages in North Queensland in 2006, and approximately $60-80 \%$ of losses arose from damage to residential construction in houses built before enhanced building standards were implemented in North Queensland from the early to mid1980s (Ginger et al. 2007). To reduce housing damage in the future it may be preferable to strengthen or retrofit existing construction. However, Stewart and Wang (2011) found such strategies often failed to be cost-effective, and if cost efficient, then only marginally so. Moreover, the existing regulatory framework in Australia constrains retrofitting existing buildings due to varying local and state government regulations, and industry would prefer to rely on changes to deemed-to-comply provisions because such provisions provide a higher level of certainty (Maddocks 2011). Other adaptation strategies may restrict construction of new housing in vulnerable (exposed) locations. Hence, an appropriate adaptation strategy may be one that increases design wind loads for new houses leading to long-term reduction of vulnerability (and damages) of houses in Queensland (Stewart et al. 2012b).

The annual probability of winds $\operatorname{Pr}(\mathrm{H} \mid \mathrm{C})$ is derived from the Generalised Pareto Distribution to model the annual probability of exceedance of cyclonic winds (winds associated with tropical cyclones), and the shifted exponential distribution to model non-cyclonic gust speed (Wang and Wang 2009). Since there are still many uncertainties to properly define the future trend of extreme winds in Australia, three possible climate scenarios (C) are:

1. 'No Change' - no change in climate

2. 'Moderate Change' $-25 \%$ reduction in cyclone frequency, and $10 \%$ increase in wind speeds by 2100 .

3. 'Poleward Shift' - 4 degree poleward shift in cyclones to South East Queensland by 2100 
We assume that $\operatorname{Pr}(\mathrm{C})=100 \%$. The variability of peak wind loads is significant with COV of up to $50 \%$. The number of existing houses in Cairns, Townsville, Rockhampton and South East Queensland are 1.1 million, which is forecast to increase to over 2.2 million by 2100 . The average replacement cost per new house (including contents) in Queensland is $\mathrm{L}=\$ 320,000$. Wind vulnerability functions are identical to those shown in Figure 7, and the loss function is given by Figure 8 .

The adaptation strategy considered herein is to design new houses by enhanced design codes, in this case, increasing the current AS4055-2006 wind classification by one category (see Table 2). These enhanced building requirements will result in additional costs of new construction $\left(\mathrm{C}_{\text {adapt }}\right)$, see Table 2 , and these adaptation costs are only 1-2\% of the value of a house. Designing new houses to enhanced wind classification will reduce vulnerability considerably, and that the risk reduction $(\Delta \mathrm{R})$ due to adaptation measures depends on wind field characteristics and location and in most cases $\Delta \mathrm{R}=90-94 \%$.

Table. 2: Current and Proposed Wind Classification (AS4055-2006), and Costs of Adaptation. Design wind speed shown in italics).

\begin{tabular}{lllc}
\hline Location & $\begin{array}{c}\text { Current Wind } \\
\text { Classification }\end{array}$ & $\begin{array}{l}\text { Proposed Wind } \\
\text { Classification }\end{array}$ & $\begin{array}{c}\text { Adaptation Cost } \\
\text { Cadapt }\end{array}$ \\
\hline Cairns, Townsville, Rockhampton & & & \\
$\quad$ Foreshore & C2 $(61 \mathrm{~m} / \mathrm{s})$ & $\mathrm{C} 3(74 \mathrm{~m} / \mathrm{s})$ & $\$ 4,500$ \\
$\quad$ Non-Foreshore & C1 $(50 \mathrm{~m} / \mathrm{s})$ & $\mathrm{C} 2(61 \mathrm{~m} / \mathrm{s})$ & $\$ 3,600$ \\
South East Queensland & & & \\
$\quad$ Foreshore & $\mathrm{N} 2(40 \mathrm{~m} / \mathrm{s})$ & $\mathrm{C} 1(50 \mathrm{~m} / \mathrm{s})$ & $\$ 2,700$ \\
$\quad$ Non-Foreshore & $\mathrm{N} 2(40 \mathrm{~m} / \mathrm{s})$ & $\mathrm{C} 1(50 \mathrm{~m} / \mathrm{s})$ & $\$ 2,700$ \\
\hline
\end{tabular}

Results are calculated using event-based Monte-Carlo simulation methods where all (foreshore and non-foreshore) new housing is designed to enhanced design standards. Any proposal to change building regulation within the Building Code of Australia would take many years. Hence, we assume an earliest time of adaptation is 2015. Costs are in 2010 Australian dollars and the discount rate is $4 \%$. For convenience, we assume that $\Delta \mathrm{B}=0$.

The 'business as usual' cumulative mean damage costs $\mathrm{E}(\mathrm{L})$ given by Eqn. (5) can increase the average of total direct and indirect losses to residential housing by $\$ 5.0$ billion by 2100 , and up to $\$ 20.5$ billion if tropical cyclones experience a poleward shift to Brisbane by 2100 . The variability of cumulative damages is also high. There is clearly a high likelihood of large potential economic losses and suggest that climate adaptation strategies may be needed to ameliorate these losses. 
Figure 11 shows if there is moderate climate change then the mean NPV can reach $\$ 3.4$ billion by 2100. Most of the benefit of adaptation strategies comes from South East Queensland due to its large population and higher vulnerability. Moreover, $\operatorname{Pr}(\mathrm{NPV}>0)$ is $92.1 \%$ indicating a very high likelihood that the adaptation strategy is cost-effective. The BCR is also quite high, for example, for moderate change the BCR is 3.02 - this means that $\$ 1$ buys $\$ 3.02$ of benefits which is a highly cost-effective outcome. Figure 11 also shows that the $10^{\text {th }}$ and $90^{\text {th }}$ percentiles of NPV can be considerable. However, they also show that there is more than 90 percent probability that NPV will exceed $\$ 158$ million for moderate change at 2100 , and that there is 10 percent probability that NPV will exceed $\$ 7.2$ billion by 2100 . Not surprisingly, the net benefit increases dramatically for the poleward shift scenario.

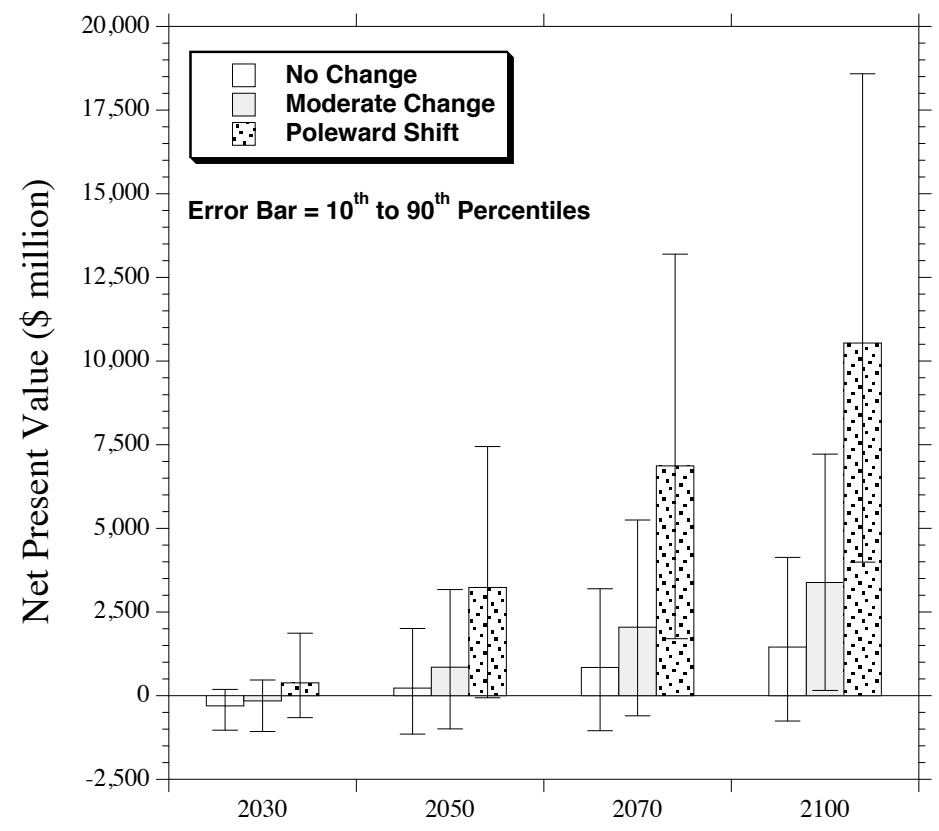

Figure 11: Mean and $10^{\text {th }}$ and $90^{\text {th }}$ percentile Net Present Values.

If there is no change in wind patterns, then some adaptation strategies are still cost-effective. For example, applying the adaptation strategy to South East Queensland will result in a mean NPV of $\$ 1.4$ billion with $70 \%$ likelihood that this benefit will occur. Hence, reduction in vulnerability, at modest cost, is a worthwhile endeavour. This is a 'no regrets' policy (Susskind 2010) even if climate predictions are wrong.

There may be economic and political benefits in deferring implementation of a climate adaptation strategy. Figure 12 shows the effect of deferring adaptation to 2020, 2030 or 2050 on mean NPV, for moderate change. It is observed that if timing of adaptation is deferred to 2020 or 2030 that the mean NPV at 2100 reduces, but that $\operatorname{Pr}(\mathrm{NPV}>0)$ is still approximately $90 \%$ for 
moderate change and for time of adaptation to 2030. The reason is that the effects of adverse climate change will become most evident later in the century, so a delay in implementing an adaptation strategy may result in immediate savings in adaptation costs, but will not reduce damage costs significantly in the short term.

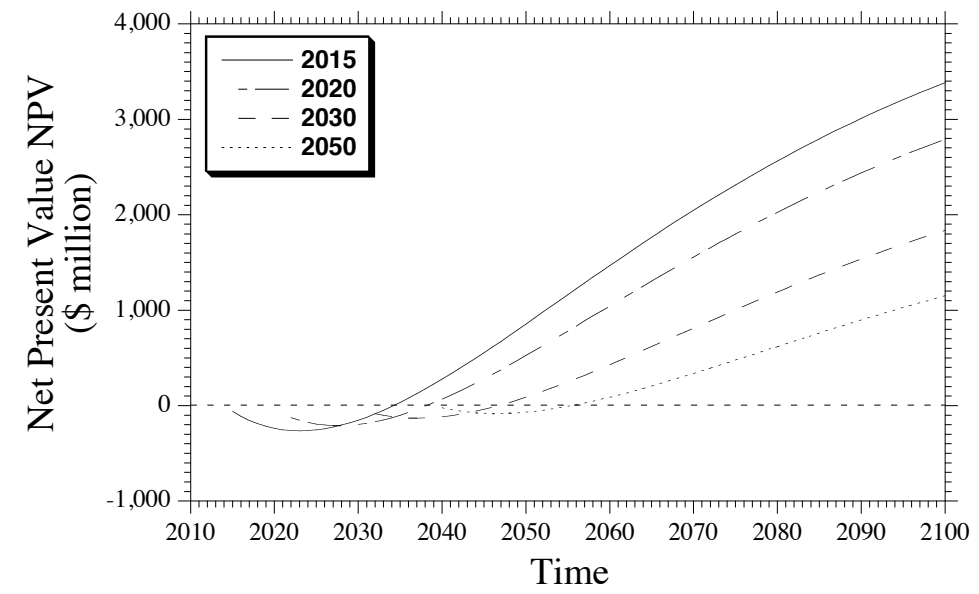

Figure 12: Influence of time of adaptation on total mean NPV, for Moderate Change.

The results are not particularly sensitive to changes in cyclone frequency, confidence interval of wind vulnerability, and non-linear time-dependent increase in wind speed. For more details see Stewart et al. (2012b).

\subsection{Climate Change and Cost-Effectiveness of Adaptation Strategies in RC Structures Subjected to Chloride Ingress}

$\mathrm{RC}$ structures are subjected to environmental actions affecting their performance, serviceability and safety. Among these actions, chloride ingress leads to corrosion initiation and its interaction with service loading could reduce its operational life. Experimental evidence indicates that chloride ingress is highly influenced by weather conditions in the surrounding environment (Saetta et al. 1993). On the other hand, studies on global warming announce several changes in climate that could affect RC durability (Bastidas-Arteaga et al. 2010, 2013, Stewart et al. 2012a). Therefore, both structural design and maintenance should be adapted to these new environmental conditions.

A preliminary cost-benefit assessment of climate adaptation measures for RC structures subject to carbonation-induced corrosion is described by Stewart and Peng (2011). This case study focuses on the assessment of the costs and benefits of a climate adaptation strategy for RC struc- 
tures placed in a chloride-contaminated environment under a more comprehensive range of climate change scenarios and structural configurations. It is supposed that the studied RC structure will be exposed to chlorides in a splash and tidal zone. According to Eurocode 2 (European Standard 2004), this condition corresponds to a XS3 exposure for which the design cover (including the allowable execution tolerance) is $c_{t 0}=55 \mathrm{~mm}$ if the structural lifecycle is 50 years. The Eurocode 2 also recommends a minimum compressive strength of $f_{c}^{\prime}=35 \mathrm{MPa}$ for this exposure.

As mentioned in Section 2, there are many uncertainties and factors influencing climate predictions. IPCC (2007) projections of global temperature rises from the baseline of 1990 range from $1.1^{\circ} \mathrm{C}$ (lower bound for $550 \mathrm{ppm}$ by 2150 emission scenario) to $6.8^{\circ} \mathrm{C}$ (upper bound for A1FI emission scenario). Projections for changes in relative humidity (RH) are less precise, however, the CSIRO Mk3.5 climate model predicts RH changes of $-16.4 \%$ to $+1.2 \%$ for Australia (Wang et al. 2012), and IPCC (2007) predicts reduced RH for Europe. For this reason, a scenario-based approach is used herein where results are presented for temperature changes, $\Delta \mathrm{T}$, of $0^{\circ} \mathrm{C}$ to $6^{\circ} \mathrm{C}$ in 100 years, and relative humidity changes, $\Delta \mathrm{RH}$, of $-10 \%$ to $+20 \%$ in 100 years. A scenario of no change in climate is also considered as engineering adaptation may make economic sense as a 'no regrets' policy even if climate predictions are wrong. It is also supposed that the structure is placed into a middle latitude (e.g., Europe, Australia, North America) for which the mean ranges of variation of temperature and relative humidity during one year are $\left[5^{\circ} \mathrm{C}, 25^{\circ} \mathrm{C}\right]$ and $[60 \%, 80 \%]$, respectively.

Deterioration modelling allows estimating the effects of chloride ingress with regard to serviceability and ultimate limit states. Ultimate limit states are highly dependent on both, geometrical characteristics (cross-sectional dimensions, span length, etc.) and loading (dead, live, seismic, etc.). Therefore, to generalise the results, this work focuses on a serviceability limit state in which the cost-effectiveness of adaptation measures is evaluated in terms of its effect on the time to corrosion damage (severe cracking or spalling of the concrete cover). This time is computed by summing the times to 'corrosion initiation', 'crack initiation' and 'crack propagation'. The time to corrosion initiation is computed using a comprehensive probabilistic model of chloride ingress that accounts for the environmental temperature and relative humidity (Bastidas-Arteaga et al. 2011). The times to crack initiation and crack propagation are computed using the models proposed by El Maaddawy and Soudki (2007) and Mullard and Stewart (2011), respectively. These times were estimated using a time-variant corrosion rate model that considers the influence of temperature and consequently global warming. A complete description of the models and their statistical parameters is presented in (Bastidas-Arteaga and Stewart 2013). 
If severe damage occurs, a likely maintenance strategy is a patch repair where the damaged concrete cover is replaced with new concrete. In addition, the time-dependent damage risks of the repaired material will not be the same as the original material due to changed temperature and humidity at the time of repair (i.e. when the concrete is new). Hence, the damage risk for repaired (new) concrete exposed to the environment for the first time at time of repair, $t_{\text {rep }}$, will change depending on the new climatic conditions and time of repairs. Figure 13 clearly shows that the rate of damage risk is highly dependent on climate change effects. If climate change reduces the environmental relative humidity, i.e. $\Delta \mathrm{RH}=-10 \%$ in 100 years, the chloride ingress mechanism slows down, and consequently, the probability of severe cracking decreases. An opposite behaviour is observed when climate change increases temperature and relative humidity.
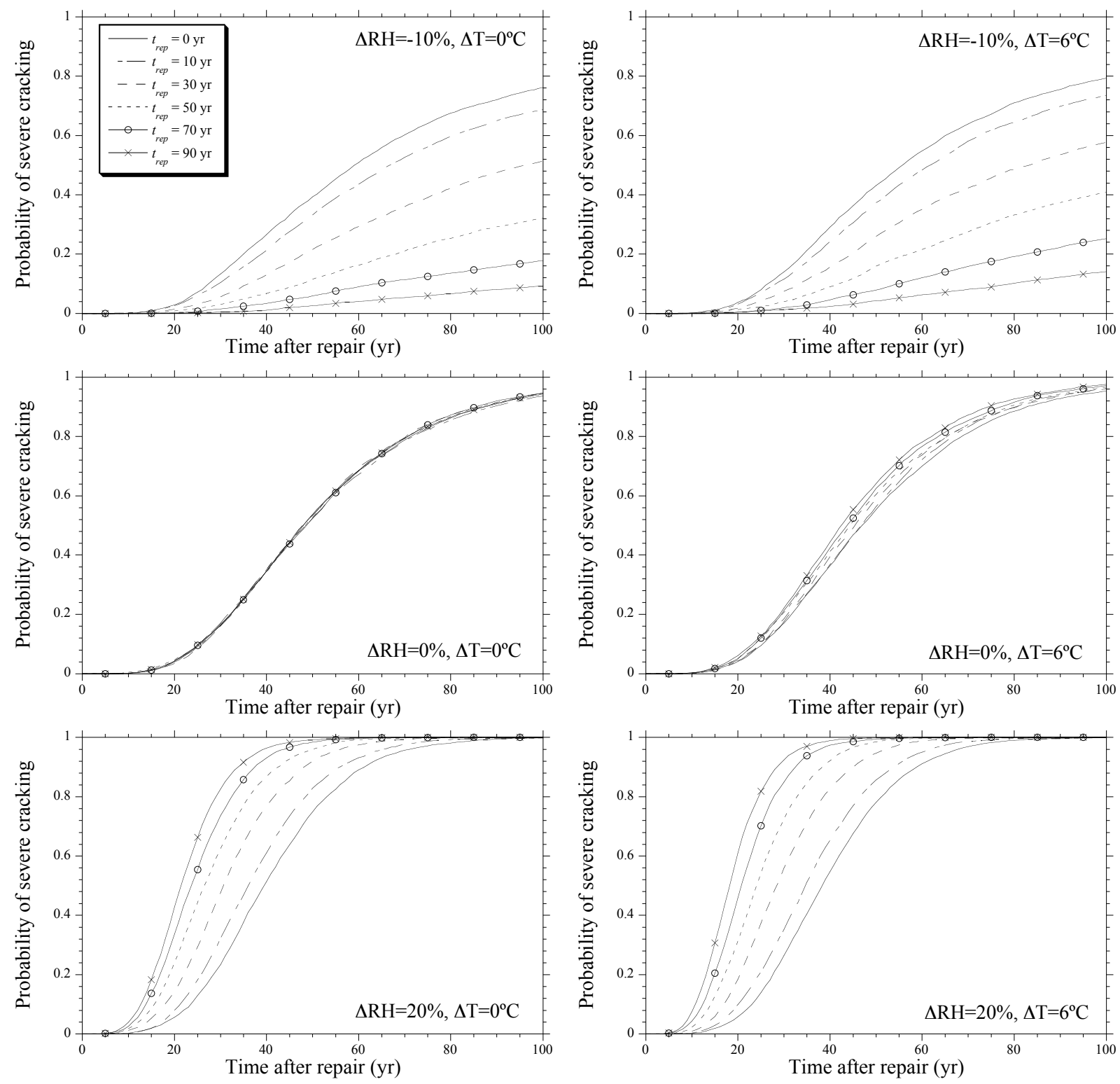

Figure 13: Probability of severe cracking for various climate change environments. 
For the modelled environmental conditions (splash and tidal zone in a middle latitude), damage risks are more sensitive to changes in relative humidity. Different sensitivities will be observed if the structure is subjected to other climate conditions. For instance, in tropical environments where there are no significant seasonal variations in temperature and relative humidity the effects of both on the probability of severe cracking will be different. Therefore, the timedependency of damage risks should be considered for a comprehensive cost-benefit analysis of adaptation measures.

The adaptation strategy consists of increases in design cover by 5 or $10 \mathrm{~mm}-$ i.e., $c_{t l}=60$ $\mathrm{mm}$ and $c_{t 2}=65 \mathrm{~mm}$. It aims to reduce the impact of chloride-induced corrosion damage by increasing the length of the corrosion initiation time and time to severe cracking. Their costeffectiveness will be measured in terms of $\mathrm{BCR}$ (equation 9) and the probability $\operatorname{Pr}(\mathrm{BCR}>1)$. Given the complexity of the models, the following results have been computed using Monte Carlo simulations.

Costs and benefits may occur at different times so in order to obtain consistent results it is necessary for all costs and benefits to be discounted to a present value. If it is assumed that corrosion damage is always detected when the structure is inspected then the expected damage cost $\mathrm{E}_{\text {damage }}\left(\mathrm{T}_{\mathrm{t}}\right)$ is the product of probability of corrosion damage and damage costs, i.e.,

$$
\mathrm{E}_{\text {damage }}\left(\mathrm{T}_{\mathrm{t}}\right)=\sum_{\mathrm{n}=1}^{\mathrm{T}_{\mathrm{t}} / \Delta \mathrm{t} \mathrm{T}_{\mathrm{t}} / \Delta \mathrm{t}} \sum_{\mathrm{i}=\mathrm{n}}\left[\mathrm{p}_{\mathrm{s}, \mathrm{n}}(\mathrm{i} \Delta \mathrm{t})-\mathrm{p}_{\mathrm{s}, \mathrm{n}}(\mathrm{i} \Delta \mathrm{t}-\Delta \mathrm{t})\right] \frac{\mathrm{C}_{\text {damage }}}{(1+\mathrm{r})^{\mathrm{i} \Delta \mathrm{t}}}
$$

where $T_{t}$ is the design structural lifecycle, $\Delta t$ is the time between inspections, $\mathrm{n}$ is the number of damage incidents, $i$ is the number of inspection, $p_{s, n}(t)$ the probability of the $n^{\text {th }}$ damage incidence before time $t, C_{\text {damage }}$ is the cost of damage including maintenance and repair costs, user delay and disruption costs, and other direct or indirect losses arising from damage to infrastructure. For example, an asset owner should be able to quantify the unit repair cost $\left(\$ / \mathrm{m}^{2}\right)$, and if the area of damage is known then repair cost can be estimated.

The cost of repair or replacement and associated user losses, etc. are considerable and for some structures user losses are often much greater than direct repair, replacement and maintenance costs. The estimated cost for concrete patch repair using ordinary Portland cement is $\$ 440 / \mathrm{m}^{2}$ (Yunovich et al. 2001, BRE 2003, Mullard and Stewart 2012). User losses and other user disruption costs are site and structure specific, but for many RC structures such costs will be minimised if the RC element to be repaired is an external structural member such as walls, columns or facade panels. However, for bridges closure of one lane for a four lane bridge can 
cause user delay costs of $\$ 61,000$ per day (Yunovich et al. 2001). To allow for a minor user disruption cost the total failure cost is assumed as $C_{\text {damage }}=\$ 500 / \mathrm{m}^{2}$.

Figure 14 presents the expected damage costs for existing cover and the two adaptation strategies for various climate change scenarios. For illustrative purposes, these results were computed for a discount rate $r=4 \%$. This value is within the range used by various government agencies - i.e. Australia 7\%, U.S. 2-3\%, UK Department of Transport, Sweden 4\% and Finland $6 \%$ (Val and Stewart 2003). The case without climate change, $\Delta \mathrm{RH}=0 \%$ and $\Delta \mathrm{T}=0^{\circ} \mathrm{C}$, is also presented in Figure 14a. It is observed that the repair costs increase when both the variations in temperature and relative humidity are most important for the existing cover and the adaptation solutions. This is explained by the increase of chloride ingress rate when the structure is exposed to higher temperature and relative humidity (Bastidas-Arteaga et al. 2010). It is also noted that adaptation strategies reduce the mean repair costs because the number of repairs is reduced and/or the time to repair is longer when there is an increase of the concrete cover. It seems that a $10 \mathrm{~mm}$ increase of the design cover is the more cheaper adaptation strategy. However, these results cannot be used to compare the cost-effectiveness of an adaptation strategy because they do not include the adaptation costs. The adaptation costs will be considered in the following BCR study.

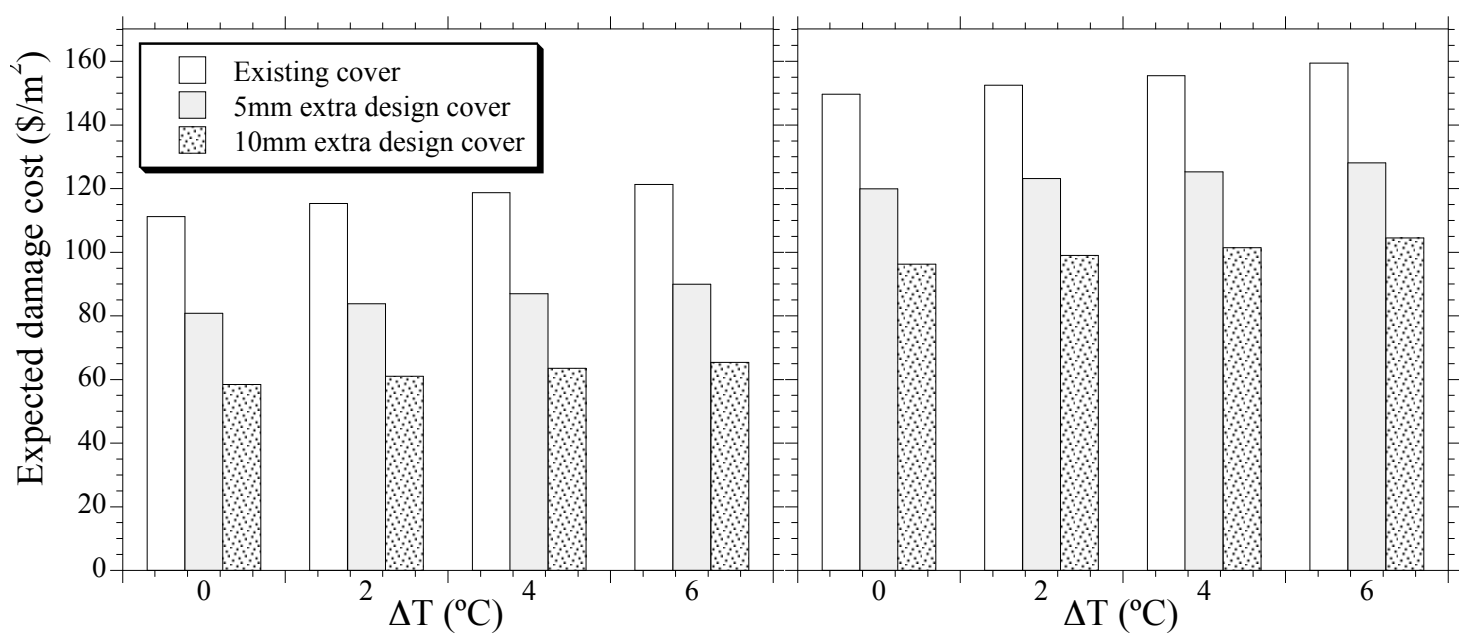

(a) $\triangle \mathrm{RH}=0 \%$

(b) $\triangle \mathrm{RH}=20 \%$

Figure 14: Expected damage cost for (a) $\Delta \mathrm{RH}=0 \%$ and (b) $\Delta \mathrm{RH}=20 \%$

Tables 3 and 4 present the mean $\mathrm{BCR}$ and $\operatorname{Pr}(\mathrm{BCR}>1)$ for various climate change scenarios. As indicated in Eqn. (9), the BCR is computed in terms of adaptation cost $C_{\text {adapt }}$. The 'benefit' is the reduction in expected damage cost due to increased cover. The value chosen in this example was computed considering that an increase in design cover would increase cost of forms, con- 
crete, reinforcement, finishing and labour by an amount proportional to the extra volume of concrete needed. These costs will also vary depending of the type of structural element and the exposed surface. For illustrative purposes, this study considers an adaptation cost of $\$ 2.4 / \mathrm{m}^{2}$ per $\mathrm{mm}$ of extra cover that corresponds to a square column $(300 \times 300 \mathrm{~mm})$ with all surfaces exposed to chlorides. For both adaptation strategies, Tables 3 and 4 indicate that the mean BCR is higher than one indicating that these adaptation measures provide benefits when compared to existing cover. When the uncertainties are included in the analysis, the results also show that $\operatorname{Pr}(\mathrm{BCR}>1)$ are all higher than $63 \%$. This indicates that the benefits of increasing concrete cover, for this aggressive environment, are important. For instance, even if no climate change is expected, i.e. $\Delta \mathrm{RH}=0 \%$ and $\Delta \mathrm{T}=0^{\circ} \mathrm{C}$, the mean $\mathrm{BCR}>2$ with a $\operatorname{Pr}(\mathrm{BCR}>1)>80 \%$.

Table. 3: Benefit-to-Cost Ratio $(B C R)$ and $\operatorname{Pr}(B C R>1)$ (shown in italics), for $C_{\text {adapt }}=\$ 12.00 / \mathrm{m}^{2}, r=4 \%$, and 5 $\mathrm{mm}$ Increase in design cover.

\begin{tabular}{lllll}
\hline & $\Delta \mathrm{T}=0^{\circ} \mathrm{C}$ & $\Delta \mathrm{T}=2^{\circ} \mathrm{C}$ & $\Delta \mathrm{T}=4^{\circ} \mathrm{C}$ & $\Delta \mathrm{T}=6^{\circ} \mathrm{C}$ \\
\hline$\Delta \mathrm{RH}=-10 \%$ & 1.73 & 2.26 & 2.51 & 2.62 \\
& $70 \%$ & $90 \%$ & $94 \%$ & $94 \%$ \\
$\Delta \mathrm{RH}=0 \%$ & 2.53 & 2.62 & 2.64 & 2.62 \\
& $89 \%$ & $92 \%$ & $94 \%$ & $96 \%$ \\
$\Delta \mathrm{RH}=10 \%$ & 2.49 & 2.41 & 2.45 & 2.46 \\
& $97 \%$ & $97 \%$ & $95 \%$ & $96 \%$ \\
$\Delta \mathrm{RH}=20 \%$ & 2.49 & 2.44 & 2.52 & 2.61 \\
& $95 \%$ & $97 \%$ & $96 \%$ & $95 \%$ \\
\hline
\end{tabular}

Table. 4: Benefit-to-Cost Ratio (BCR) and $\operatorname{Pr}\left(B C R>1\right.$ ) (shown in italics), for $C_{\text {adapt }}=\$ 12.00 / \mathrm{m}^{2}, r=4 \%$, and 10 $\mathrm{mm}$ Increase in design cover.

\begin{tabular}{lllll}
\hline & $\Delta \mathrm{T}=0^{\circ} \mathrm{C}$ & $\Delta \mathrm{T}=2^{\circ} \mathrm{C}$ & $\Delta \mathrm{T}=4^{\circ} \mathrm{C}$ & $\Delta \mathrm{T}=6^{\circ} \mathrm{C}$ \\
\hline$\Delta \mathrm{RH}=-10 \%$ & 1.54 & 1.95 & 2.17 & 2.33 \\
& $63 \%$ & $80 \%$ & $86 \%$ & $88 \%$ \\
$\Delta \mathrm{RH}=0 \%$ & 2.20 & 2.26 & 2.30 & 2.33 \\
& $84 \%$ & $89 \%$ & $92 \%$ & $94 \%$ \\
$\Delta \mathrm{RH}=10 \%$ & 2.20 & 2.21 & 2.19 & 2.22 \\
& $94 \%$ & $94 \%$ & $92 \%$ & $94 \%$ \\
$\Delta \mathrm{RH}=20 \%$ & 2.22 & 2.23 & 2.25 & 2.29 \\
& $95 \%$ & $95 \%$ & $96 \%$ & $94 \%$ \\
\hline
\end{tabular}

On the other hand, as presented in Figure 13, some 'positive' effects of climate change on concrete durability could be attended if RH decreases with time. These positive effects will therefore reduce the costs-effectiveness of adaptation measures. For instance, if the relative humidity 
decreases (i.e., $\Delta \mathrm{RH}=-10 \%$ ), the chloride ingress rate will also decrease diminishing the number of repairs and consequently repair costs. In such a case, Table 3 indicates that the mean BCRs computed when $\Delta \mathrm{RH}=-10 \%$ are generally lower than the computed for the case when $\Delta \mathrm{RH}=0 \%$. This means that the benefits of the adaptation measures could be lower under some climate change conditions. However, mean BCR still exceeds one. Therefore, the effects of climate adaptation measures should be carefully evaluated in order to decide if they provide benefits of losses with respect to the existing design.

Finally, comparing both adaptation strategies, it is noted that an increase of $5 \mathrm{~mm}$ cover provides higher estimates of $\mathrm{BCR}$ and $\operatorname{Pr}(\mathrm{BCR}>1)$. Therefore, for this configuration under the above-defined environmental conditions an increase in design cover of $5 \mathrm{~mm}$ is recommended as a cost-effective climate change adaptation measure. More details on this study including other structural elements and exposure conditions are described by Bastidas-Arteaga and Stew$\operatorname{art}(2013)$.

\subsection{Designing on- and Offshore Wind Energy Installations to Allow for Predicted Evolutions in Wind and Wave Loading}

Wind energy is becoming ever more prominent around the globe with $237 \mathrm{GW}$ of installed capacity at the end of 2011, an equivalent of providing for approximately $3 \%$ of the global electricity demand (Gsänger and Pitteloud 2012). The European offshore wind target is $460 \mathrm{GW}$ installed capacity by 2050 , as compared to the worldwide target of $1150 \mathrm{GW}$, with a market for offshore energy investments in the European Union in the region of $€ 360$ billion. For the first decade of the $21^{\text {st }}$ century there has been an average annual growth of $30 \%$ and a long-term trend that sees the global installed capacity doubling every third year. Onshore wind turbines account for the majority of wind generated electricity in the global energy market, accounting for $99.5 \%$ of the installed capacity at the end of 2011 (Gsänger and Pitteloud 2012). It is noted by Hau (2006) that an energy yield of $30-40 \%$ higher than that on land can be expected from offshore applications due to the higher and more consistent wind speeds. Ferguson (1998) highlights the improved turbulence characteristics observed offshore with typical values of about $8 \%$ at a height of $60-70 \mathrm{~m}$ compared to turbulence intensities over land within a range of $10-20$ $\%$. This has a major effect on the fatigue loading of the turbine structures.

Despite the prospects of wind energy, there are many barriers that must be overcome in order to improve the extent of its viability as an energy source. One such barrier is accounting for the unpredictable nature of climate change and its effect on wind energy infrastructure in the future. The rise in the average global temperature and its associated effects on global weather patterns 
with increased frequency of devastating storms and hurricanes poses the greatest threat to wind energy infrastructure installations due to the inherent requirement to locate wind turbines at exposed locations in order to benefit from more reliable wind speeds. Typically, wind turbines start generating electricity once the wind speed has reached $3-4 \mathrm{~m} / \mathrm{s}$ and meet their rated output at around $13 \mathrm{~m} / \mathrm{s}$, the shut-off condition is at about $25 \mathrm{~m} / \mathrm{s}$ to prevent damage to generator and other components (Singh 2007). Clearly, the rated design wind speeds of these turbines, along with the maximum safe operating speeds, will have to adapt to accommodate changes in wind behaviour. In this context it should be borne in mind that, modern wind turbine designs aim to increase power output by reaching higher into the atmosphere, supported by taller towers, and by possessing larger rotor diameters in order to capture greater amounts of the passing airflow.

In considering the design of wind turbine installations the primary loading component is the force of the wind impacting on the structure. For offshore wind turbines the hydrodynamic loading induced by waves is also a considerable component. Considering the wind conditions, the British and European standard of wind turbine design BS EN 61400-1 (2005) has specified three wind turbine classes dependent on the wind speed and turbulence parameters of the intended site. Having specified a wind turbine class it is necessary to analyse the structure for a set of design load case (DLC) events. The standard requires the use of a structural dynamics model to predict the design load effects. Considered among the DLC events which must be analysed are environmental conditions represented by a Normal Wind Profile, Normal Turbulence Model, Extreme Wind Model, Extreme Turbulence Model, Extreme Coherent Gust With Direction Change, Extreme Wind Shear, Extreme Operating Gust, and Extreme Direction Change. The DLCs are configured to simulate a variety of situations including normal power production, power production with a fault occurrence, a start up event, normal shut down, emergency shut down, parked conditions, parked with a fault and transportation. While the turbine must be capable of resisting the most extreme wind conditions for the ultimate limit-state (ULS), it is often the fatigue loading of the turbine which dictates the design.

Offshore wind turbines are subjected to additional loading conditions which must be considered in the design. BS EN 61400-3 (2009) defines a wind turbine as an offshore wind turbine if the support structure is subject to hydrodynamic loading. These additional marine induced effects such as loads due to waves, sea currents, tidal fluctuation in water level, sea ice, marine growth, seabed movement and scour must be considered in the design. Noting the unpredictable nature of waves, it is suggested that the features of a real sea are best reflected by describing a sea state by means of a stochastic wave model. Considerable research has been conducted on the topic of wave modelling for offshore wind turbines (Marino et al. 2011a,b, Agarwal and Manuel 2011, Jensen et al. 2011, Chella et al. 2012). BS EN 61400-3 (2009) and DNV-OS-J101 (2010) 
suggest the use of a spectral model for the simulation of the sea state. The Pierson-Moskowitz spectrum is applicable to a fully developed sea state while the JONSWAP spectrum pertains to a developing sea state for events such as a storm situation. The correlation of wind and wave conditions must also be addressed (Colwell and Basu 2009). As these conditions are affected by local site factors such as fetch, water depth and bathymetry, the determination of parameters must be made from suitable long term measurements.

Due to the stochastic nature of both the loading on- and response of wind turbine support structures the implications of climate change for the design/assessment of infrastructure installations is best assessed in a structural reliability analysis framework. A primary facet of reliability based analysis is the development of fragility curves. Fragility curves describe the probability of a structure exceeding a prescribed limit-state given an input hazard intensity parameter, see Eqn. (7) and Figure 7. Dueñas Osorio and Basu (2008) developed wind-induced acceleration fragility curves in combination with an annual distribution of the wind hazard in order to predict the risk of malfunction of acceleration-sensitive equipment in wind turbines.

In this context, for the purpose of illustrating the implications of climate change on wind turbine design, it is intended to employ fragility curves in a simple example, which relates wind hazard intensity to a tower limit-state, as a method for comparing the relative structural performance of the wind turbine towers considered. A displacement based fragility curve generation procedure is utilised, based upon a limit-state related to nacelle (tower-tip) displacement. The choice of displacement limit-state reflects the stability of the tower structure and its ability to resist the prescribed loading conditions. Mean hub-height wind speed has been chosen as the fragility hazard parameter as it is quite straightforward and it dictates the underlying turbulent parameters of the wind speed. The fragility term employed in this analysis is represented as:

$$
\operatorname{Pr}(\mathrm{D} \mid \mathrm{H})=\operatorname{Pr}\left(\mathrm{d}_{\text {tip }}>\mathrm{LS} \mid \overline{\mathrm{V}}_{\text {hub }}=\overline{\mathrm{V}}\right)
$$

where $d_{\text {tip }}$ is the maximum nacelle displacement, LS is the tower limit-state (maximum allowable deflection), and $\overline{\mathrm{V}}$ is the mean hub-height wind speed.

The wind turbine model employed in the analyses is adapted from a model outlined by Hansen (2003) in a study of stall-induced vibrations in wind turbines. Similar formulations have been employed by Arrigan et al. (2011) and Quilligan et al. (2012). The current model is derived as a two dimensional dynamic interpolation of the vibrational behaviour of the entire wind turbine system. Employing a modal approximation for the flexible blade and tower components, it also takes account of nacelle tilt, roll and yaw as well as rotor shaft rotation as described in Figure 15. 
The Lagrangian formulation is utilised to obtain the dynamic equations of motion by directly minimising the total energy functions of the dynamical system. Lagrange's equation, as defined in Clough and Penzien (1993). This approach allows all elements of coupling to be accurately referenced in the system of differential equations describing the dynamics (Quilligan 2013).

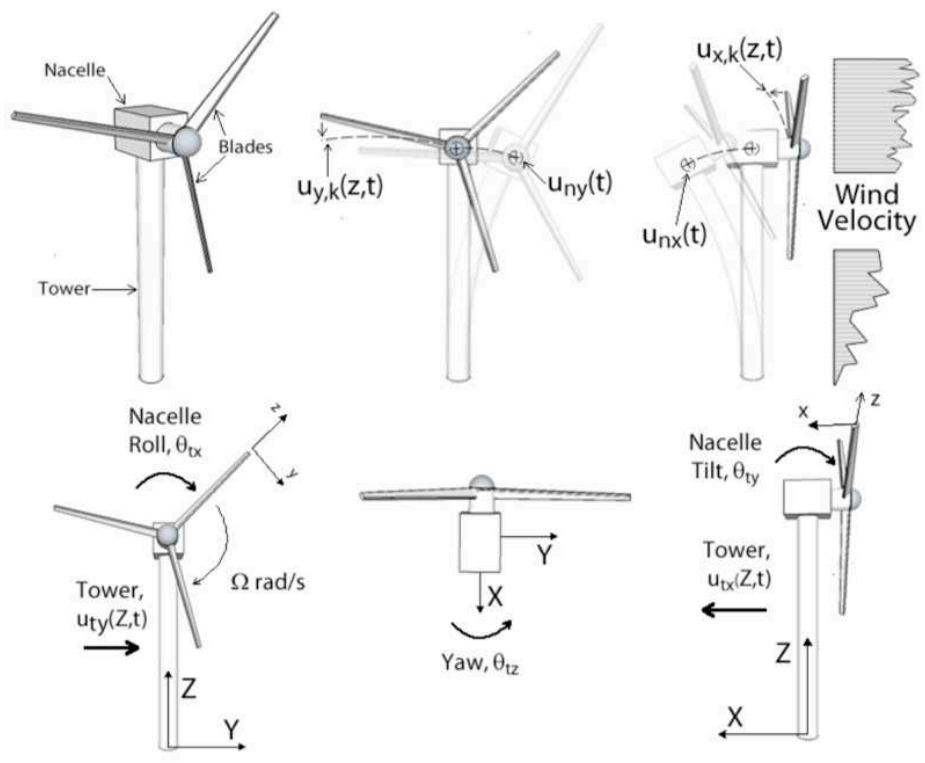

Figure 15: Wind turbine configurations (Quilligan et al. 2012).

The external loading applied to the system is contributed by the fluctuating wind field. As the wind passes through a turbine it imparts both a lift and drag force upon the blades. The wind inflow, $V_{0}=\bar{V}+V^{\prime}(t)$ is modelled as a stochastic wind model with a fluctuating component $V^{\prime}(t)$, as well as a mean component, $\bar{V}$, which includes the effects of wind shear. As the blades rotate about the hub their vertical position above the ground varies periodically. This is significant for large turbines where rotor diameters can extend beyond $100 \mathrm{~m}$ and a significant height difference exists between the bottom and top of the rotor arc. The effect of wind shear is accounted for in this case by the log law:

$$
\overline{\mathrm{v}}(\mathrm{Z})=\frac{1}{\mathrm{k}} \mathrm{v}_{*} \ln \frac{\mathrm{Z}}{\mathrm{Z}_{0}}
$$

in which $Z$ is the height above the surface, $\bar{v}(Z)$ is the mean wind velocity at height $Z, v_{*}$ is the friction velocity, $\mathrm{k}$ is the Von-karman constant, and $\mathrm{Z}_{0}$ is the roughness length. Figure 16 presents a sample of a generated wind velocity time-history with a prescribed mean value of zero and standard deviation of $2.29 \mathrm{~m} / \mathrm{s}$. This is a typical value for mean wind speeds of $18 \mathrm{~m} / \mathrm{s}$ with 
low turbulence characteristics (BS EN 61400-1 2005). BS EN 61400-1 (2005) assumes that the longitudinal turbulence standard deviation $\sigma_{l}$ is invariant with height. This is deemed a valid assumption, having been also implemented by the design standard DNV-OS-J101 (2010) and was demonstrated to have sufficient accuracy by Bowen (2008). The code also suggests that a coherence model be specified to correlate the turbulence effects across the entire rotor. In this instance uniform turbulence is assumed for the blades.

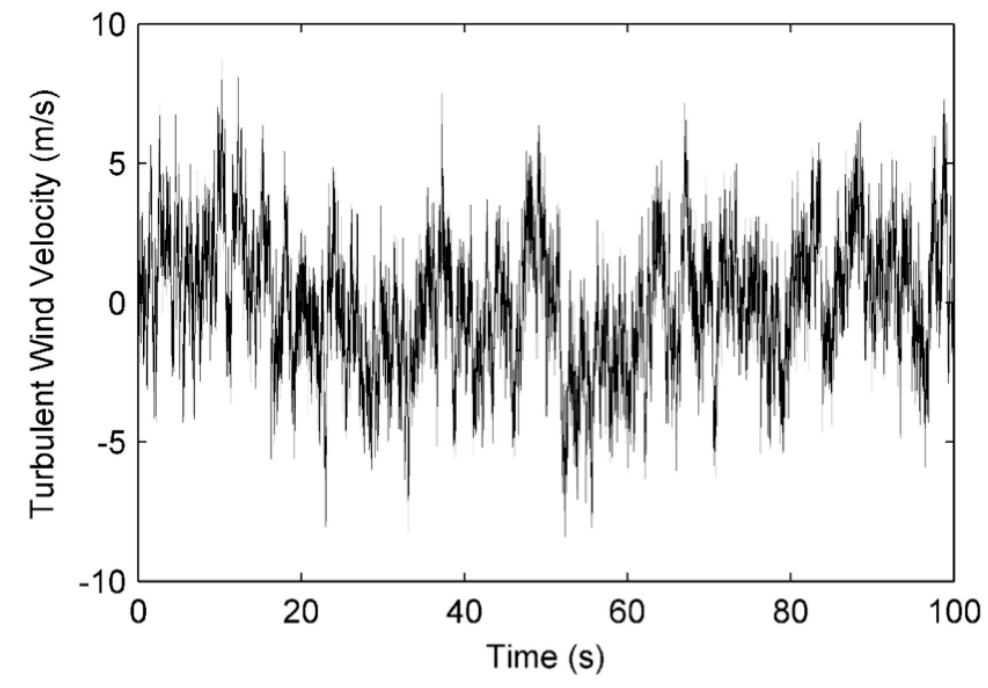

Figure 16: Wind velocity time-history.

The loading on the tower is calculated in a similar fashion to the blades except the coherence of the fluctuating drag force component was taken account of by implementing a formulation proposed by Nigam and Narayanan (1994) and successfully implemented by Murtagh et al. (2005) and Colwell and Basu (2009). This identifies the modal fluctuating drag force power spectrum for a continuous line-like structure, which is discretised into a MDOF dynamic system (Quilligan et al. 2012).

For the implementation of the current analytical study a representative multi-megawatt wind turbine has been chosen. The turbine in question is the NREL offshore baseline $5 \mathrm{MW}$ wind turbine which has an equivalent tubular steel tower for onshore installations (Jonkman et al. 2009). The key properties of the turbine are listed in Table 5. 
Table. 5: Key properties of NREL baseline $5 \mathrm{MW}$ wind turbine (Jonkman et al. 2009).

\begin{tabular}{ll}
\hline Property & Value \\
\hline Rating & $5 \mathrm{MW}$ \\
Rotor Diameter & $126 \mathrm{~m}$ \\
Hub Diameter & $3 \mathrm{~m}$ \\
Hub Height & $90 \mathrm{~m}$ \\
Cut-in Wind Speed & $3 \mathrm{~m} / \mathrm{s}$ \\
Rated Wind Speed & $11.4 \mathrm{~m} / \mathrm{s}$ \\
Cut-out Wind Speed & $25 \mathrm{~m} / \mathrm{s}$ \\
Cut-in Rotor Speed & $6.9 \mathrm{rpm}$ \\
Rated Rotor Speed & $12.1 \mathrm{rpm}$ \\
Nacelle Mass & $240,000 \mathrm{~kg}$ \\
Rotor Mass & $110,000 \mathrm{~kg}$ \\
Blade Material & $\mathrm{Glass}-\mathrm{fibre}$ \\
Blade Length & $61.5 \mathrm{~m}$ \\
Blade Mass & $17,740 \mathrm{~kg}$ \\
Blade CM (From Blade Root) & $20.475 \mathrm{~m}$ \\
Blade Damping Ratio (All Modes) & $0.48 \%$ \\
\hline
\end{tabular}

Given the current trend towards increasing tower heights, three tower heights are considered. The NREL 5MW baseline onshore wind turbine tower (Jonkman et al. 2009) is considered for the $88 \mathrm{~m}$ tower height, with a resulting hub location at $90 \mathrm{~m}$. The $103 \mathrm{~m}$ tower for the Vestas V$903 \mathrm{MW}$ wind turbine (Vestas 2004, 2005) is scaled up to accommodate the additional mass of the $5 \mathrm{MW}$ turbine unit, for an overall hub height of $105 \mathrm{~m}$. A third tower of $120 \mathrm{~m}$, which is close to the current maximum height of state of the art prototype multi-megawatt wind turbines, is considered with a resulting hub height of $122 \mathrm{~m}$. The properties of this tower are estimated from a scaling of the properties of the other two towers as no material was sourced for steel towers of this height. In all cases the tower diameter and steel thickness is assumed to taper linearly from bottom to top. Details of the key tower properties are outlined in Table 6.

Table. 6: Key properties of NREL baseline $5 \mathrm{MW}$ wind turbine (Jonkman et al. 2009).

\begin{tabular}{|c|c|c|c|}
\hline Property & $88 \mathrm{~m}$ Tower & 103 m Tower & $120 \mathrm{~m}$ Tower \\
\hline Height & $87.6 \mathrm{~m}$ & $103 \mathrm{~m}$ & $120 \mathrm{~m}$ \\
\hline Base Diameter & $6 \mathrm{~m}$ & $7.2 \mathrm{~m}$ & $8.43 \mathrm{~m}$ \\
\hline Base Steel Thickness & $0.035 \mathrm{~m}$ & $0.041 \mathrm{~m}$ & $0.048 \mathrm{~m}$ \\
\hline Top Diameter & $3.87 \mathrm{~m}$ & $3.87 \mathrm{~m}$ & $3.87 \mathrm{~m}$ \\
\hline Top Steel Thickness & $0.025 \mathrm{~m}$ & $0.025 \mathrm{~m}$ & $0.025 \mathrm{~m}$ \\
\hline Young's Modulus (GPa) & $\operatorname{LN}(210,3)$ & $\operatorname{LN}(210,3)$ & $\operatorname{LN}(210,3)$ \\
\hline Steel Density $\left(\mathrm{kg} / \mathrm{m}^{3}\right)^{\&}$ & $N(8500,1)$ & $N(8500,1)$ & $N(8500,1)$ \\
\hline Total Mass & $356,620 \mathrm{~kg}$ & $535,850 \mathrm{~kg}$ & $798,640 \mathrm{~kg}$ \\
\hline Location of CM (Above Base) & $35.967 \mathrm{~m}$ & $39.2 \mathrm{~m}$ & $43.042 \mathrm{~m}$ \\
\hline Tower Damping Ratio (All Modes) & $1 \%$ & $1 \%$ & $1 \%$ \\
\hline
\end{tabular}

${ }^{\$}$ Log Normally distributed with $\mathrm{LN}(\mathrm{m}, \mathrm{CoV}),{ }^{\text {\& }}$ Normally distributed with $\mathrm{N}(\mathrm{m}, \mathrm{CoV})$. 
The simulations produce sets of displacement, velocity and acceleration time histories for the response of the towers and blades examined in the current study. Tower maximum displacement is chosen as a simple variable with which to perform a relative comparison of the results for various tower configurations and for increasing mean hub wind speed, which may be considered to represent the climate change evolution. Fragility curves are developed, Figure 17, to compare the relative performance of the various tower configurations. In a similar manner fragility curves may be developed to study the implications for blade tip displacements and associated fatigue life of towers and of M\&E components etc. with respect to climate evolutions, i.e. in the form of increasing wind speeds, increased storm frequency with associated surge characteristics, modifications to load combination rules, etc.

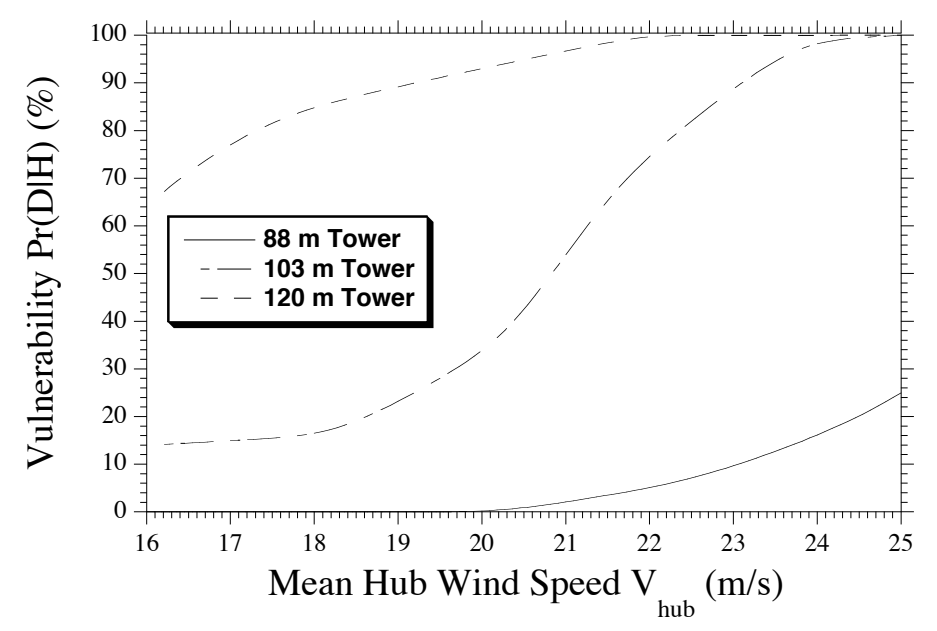

Figure 17: Fragility curves for considered tower height and wind speed.

With the increased regularity and growing size of the storms generated by our planet's weather system it is obvious that this will affect the design of wind turbine structures. The entire structural system must be designed to withstand the increasing wind speeds and wave heights experienced on a more regular basis, while sophisticated configurations must be adopted in order to protect sensitive mechanical components during such an event. A particularly unnerving factor witnessed in recent climate change effects is the unpredictable nature of the resulting weather patterns. Engineers and insurers must accurately quantify the lifetime levels of risk of structural failure (collapse and operational limits) for wind turbines taking all uncertainties into account. Currently, there exists hardly any guidance or research in quantifying the risks of wind turbines exposed to such uncertain loadings. It is proposed here that the use of fragility curves can provide an appropriately robust tool for this purpose. 


\section{5 impact and Adaptation to Coastal Inundation}

Storm tide is defined as the sum of a mean sea level, astronomical tide, storm surge, and wave setup. Sea level rise increases the mean sea level, which is likely to lead to an increase in coastal inundation. This case study investigates the direct damage losses and adaptation benefits for residential buildings under storm tides and projected sea-level rises in Southeast Queensland (SEQ), the fastest growing region within Australia in the last two decades.

The current storm-tide hazard is based on the latest storm-tide research by Hardy et al. (2004), which indicated $1.57 \mathrm{~m}$ for Average Recurrence Interval (ARI) of 100 years, and $1.82 \mathrm{~m}$ for ARI=500 years. Meanwhile, the future inundation hazards are simulated by taking into account sea level rises from IPCC's A1FI scenario, which is $0.3 \mathrm{~m}$ by 2050 and $0.8 \mathrm{~m}$ by 2100 . As shown in Figure 18, the inundation hazard maps corresponding to a series of return periods were generated by an iterative quasi-dynamic simulation process where sea water gradually rises and permeates inland in consideration of connectivity to the inundation source. Residential buildings exposed to the inundation may incur damage and loss depending on water depth.

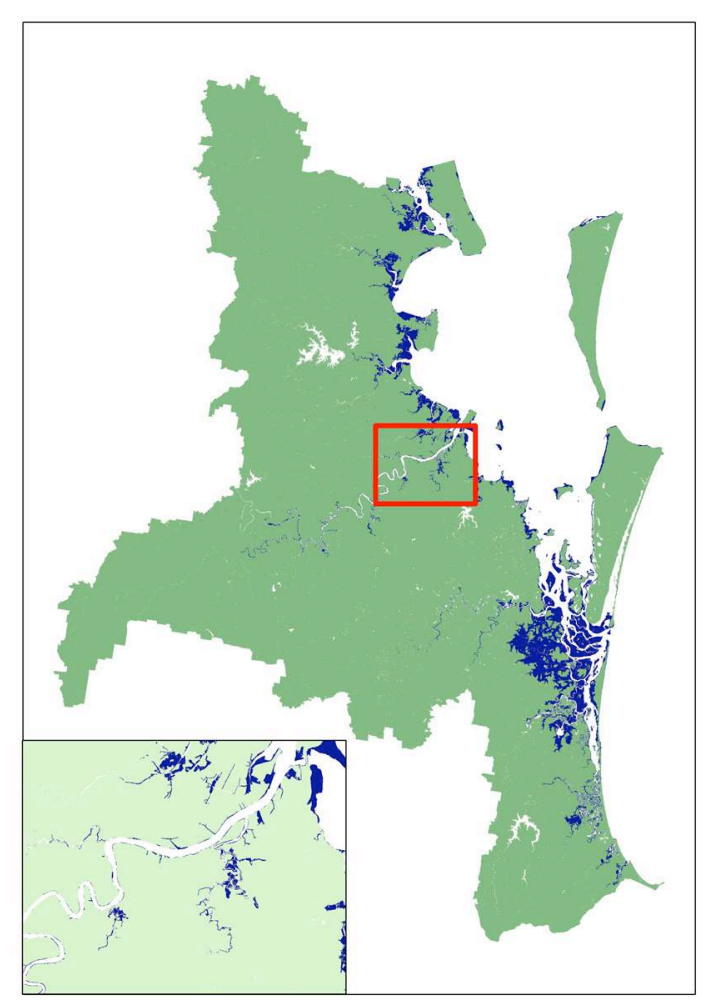

(a) 2006

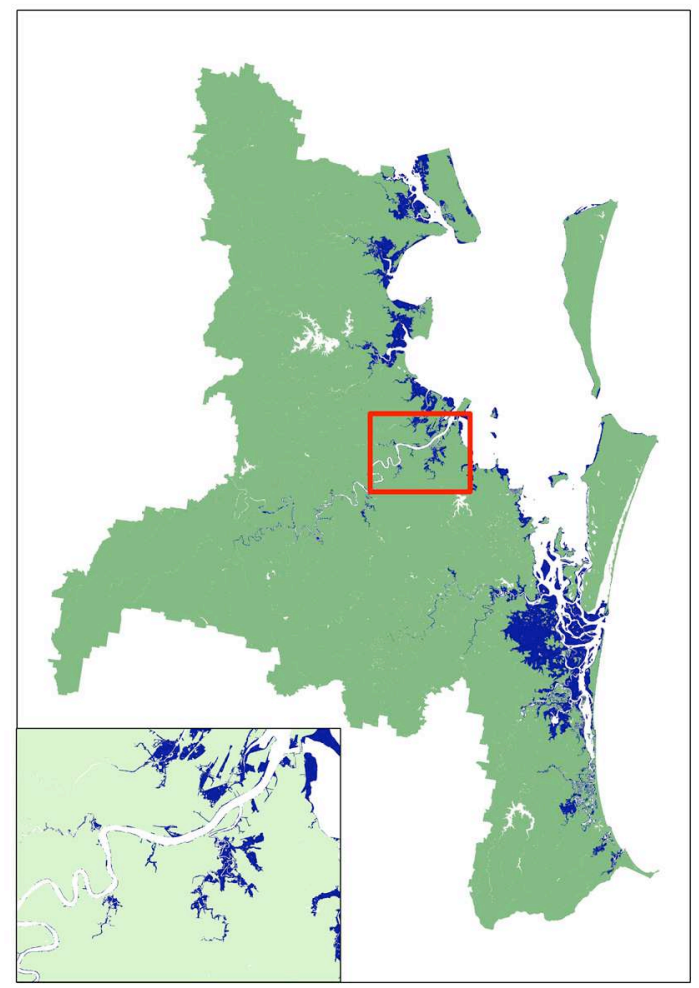

(b) 2056

Figure 18: Coastal inundation in SEQ as a result of 1-in-20 year storm tide and sea level rise. 
Facing the risks to more storm-tide inundation in the future, a decision has to be made on what is the most cost-effective approach to adapt to the future hazards. For this purpose, we link the adaptation decision-making process more specifically with the answer to the research question: What storm-tide return period, which decides the inundated coastal areas, should be considered in the planning for coastal residential buildings to achieve cost-effective adaptations.

It was found that the benefit of raising the floor height of existing buildings is marginal in the long term. When the adaptation area is smaller than the inundated area for a 20 -year storm tide under current hazard the benefit-cost ratio with time is always larger than 1 . The longer the adaptation policy horizon, the larger the adaptation area is required to attain the optimal benefit; e.g. for policy horizons of 2050, 2070, and 2090, the optimal adaptation areas need be the areas of 20-, 600-, and 3500-year inundation extents, respectively, giving the benefit-cost ratios of $1.2,1.3$, and 1.9, respectively. These findings indicate that constructing new buildings with higher flood heights is a relatively inexpensive but highly effective approach to alleviate future damage losses by storm-tide inundation.

\section{RESEARCH CHALLENGES}

Civil infrastructure is responsible for serving human activities and/or protecting human lives and assets. Thus, under evolving climatic conditions, climate adaptation engineering requires important research efforts to minimise the impacts of climate change on civil engineering infrastructure and consequently on those whom it serves. Currently, infrastructure is mainly designed/assessed to withstand more or less well-know environmental conditions and/or natural hazards. However, as has been shown in this chapter, designing/assessing infrastructure for the effects of climate change will require revision to accepted models of deterioration and of both the occurrence rates of natural hazards and their frequency of combination. Consideration of Black Swans, i.e. extremely rare events which have never been encountered before, must also enter the arena (Paté-Cornell 2012). Therefore, more interdisciplinary research is required to improve the understanding of the behaviour of infrastructural elements/networks under new climatic conditions including extreme events as well as to improve the evaluation of the costeffectiveness of adaptation measures. Some of the interacting fields are: climatology, economy, social sciences, engineering, etc. Exchanges between climatologists and engineers will contribute to a better understanding of climate effects for specific zones facilitating quantification of expected extreme storms, increases in sea level, changes in weather conditions, considering Black Swans etc. They also could develop simplified climate change models that take into account the main trends of AOGCMs and the local structural conditions. The interaction with ec- 
onomists and/or other social sciences could be useful for extending existing methods for costs analysis not commonly used in civil engineering or to develop new methods considering intergenerational effects and costs related with environmental impact $\left(\mathrm{CO}_{2}\right.$ emissions, waste generation, etc.) as well as societal effects. Co-operation in defining/optimising infrastructure provision/performance from the perspective of the Life Quality Index will also be of significant importance (Rackwitz 2002).

\section{CONCLUSIONS}

There is clear evidence that the performance of new and existing infrastructure will degrade if subject to more extreme climate-related hazards or accelerated climate-change induced degradation of material properties. Climate adaptation engineering involves estimating the risks, costs and benefits of climate adaptation strategies (retrofitting, strengthening, enhanced designs) and assessing at what point in time climate adaptation becomes economically viable. This chapter has described how risk-based approaches are well suited to optimising climate adaptation strategies related to the design and maintenance of existing infrastructure. The concepts were illustrated with state-of-the-art applications of risk-based assessment of climate adaptation strategies including: (i) resilience of interdependent infrastructure systems to floods, (ii) design of new houses in Queensland subject to tropical cyclones, (iii) evaluation of effects of climate change and cost-effectiveness analysis of adaptation strategies in reinforced concrete structures subjected to chloride ingress, (iv) designing on- and offshore wind energy installations to allow for predicted evolutions in wind and wave loading, and (v) impact and adaptation to coastal inundation.

\section{ACKNOWLEDGEMENTS}

The support provided to Professor Mark G. Stewart by the CSIRO Climate Adaptation Flagship Climate Adaptation Engineering for Extreme Events Cluster is greatly appreciated.

\section{REFERENCES}

Agarwal, P. \& Manuel, L. (2011) Incorporating irregular nonlinear waves in coupled simulation and reliability studies of offshore wind turbines, Applied Ocean Research, 33(3), 215-227.

American Institute of Architects. (1999) Environmental Resource Guide, Wiley. 
Arrigan, J., Pakrashi, V., Basu, B. \& Nagarajaiah, S. (2011) Control of flapwise vibra- tions in wind turbine blades using semi-active tuned mass dampers, Structural Control and Health Monitoring, 18(8), 840-851.

AS4055-2006 Wind Loads for Houses, Standards Australia, Sydney.

ATSE (2008) Assessment of Impacts of Climate Change on Australia's Physical Infrastructure, The Australian Academy of Technological Sciences and Engineering, Canberra.

Bastidas-Arteaga, E., Chateauneuf, A., Sánchez-Silva, M., Bressolette, Ph. \& Schoefs, F. (2010) Influence of weather and global warming in chloride ingress into concrete: a stochastic approach, Structural Safety, 32, 238-249.

Bastidas-Arteaga E., Chateauneuf, A., Sánchez-Silva, M., Bressolette, P. \& Schoefs F. (2011) A comprehensive probabilistic model of chloride ingress in unsaturated concrete. Engineering Structures, 33, 720-730.

Bastidas-Arteaga, E., Schoefs, F., Stewart, M.G. \& Wang, X. (2013) Influence of weather and global warming in chloride ingress into concrete: a stochastic approach, Engineering Structures, 51, 259-266.

Bastidas-Arteaga, E. \& Stewart, M.G. (2013) Probabilistic Cost-Benefit Analysis of Climate Change Adaptation Strategies for New RC Structures Exposed to Chloride Ingress, In: 11th International Conference on Structural Safety \& Reliability, June 16-20, New York, NY.

Blain, G.C. (2011) Incorporating climate trends in the stochastic modeling of extreme minimum air temperature series of Campinas, state of Sao Paulo, Brazil. Bragantia, 70(4), 952-957.

Boardman, A.E., Greenberg, D.H., Vining, A.R. \& Weimer, D.L. (2011) Cost-Benefit Analysis: Concepts and Practice, Pearson, Boston.

Bowen, B. M. (2008) Analysis of turbulence profiles from three tall towers: departure from similarity theory in near-neutral and stable conditions, The Open Atmospheric Science Journal, 2(1), 106-116.

BRE (2003) Residual Life Models for Concrete Repair - Assessment of the Concrete Repair Process, Building Research Establishment, UK.

BS EN 61400-1 (2005) Wind Turbines - Part 1: Design Requirements. British Standards Institution. 
BS EN 61400-3 (2009) Wind Turbines - Part 3: Design Requirements for Offshore Wind Turbines, British Standards Institution.

BTE (2001) Economic Costs of Natural Disasters in Australia, Bureau of Transport Economics Report 103, Canberra.

Burton, A., Fowler, H.J., Blenkinsop, S. \& Kilsby, C.G. (2010) Downscaling transient climate change using a Neyman-Scott Rectangular Pulses stochastic rainfall model. Journal of Hydrology, 381(1-2), 18-32.

Cavallo, E. \& Noy, I. (2010) The Economics of Natural Disasters: A Survey, IDB Working Paper Series No. IDB-WP-124, Inter-American Development Bank, Washington, D.C.

Chella, M. A., Tørum, A. \& Myrhaug, D. (2012) An overview of wave impact forces on offshore wind turbine substructures, Energy Procedia, 20(0), 217-226.

Chen, J., Brissette, F.P. \& Leconte, R. (2010) A daily stochastic weather generator for preserving low-frequency of climate variability. Journal of Hydrology, 388(3), 480-490.

Clough, R. W. \& Penzien, J. (1993) Dynamics of Structures, 2 edn., McGraw-Hill, Singapore.

CNA (2007) National Security and the Threat of Climate Change, The CNA Corporation, Alexandria, Virginia.

Coles, S. (2001) An Introduction to Statistical Modelling of Extreme Values. Springer-Verlag, London.

Colwell, S. \& Basu, B. (2009) Tuned liquid column dampers in offshore wind turbines for structural control, Engineering Structures, 31(2), 358-368.

DNV-OS-J101 (2010) Design of Offshore Wind Turbine Structures. Offshore Standard DNVOS-J101. Norway: Det Norske Veritas.

Dueñas Osorio, L. \& Basu, B. (2008) Unavailability of wind turbines due to wind- induced accelerations, Engineering Structures, 30(4), 885-893.

DuratiNet (2012) Repair and Green Concrete, Technical Report TR6.1, www.duratinet.org

EEA (2012) Urban adaptation to climate change in Europe Challenges and opportunities for cities together with supportive national and European policies, EEA Report No 2/2012, European Environment Agency, Copenhagen, Denmark. 
Ellingwood, B.R. (2006) Mitigating Risk from Abnormal Loads and Progressive Collapse, Journal of Performance of Constructed Facilities, 20(4), 315-323.

Ellingwood, B. R., Celik, O. C. \& Kinali, K. (2007) Fragility assessment of building structural systems in Mid-America, Earthquake Engineering \& Structural Dynamics, 36(13), 19351952.

El Maaddawy, T. \& Soudki, T. (2007) A model for prediction of time from corrosion initiation to corrosion cracking, Cement \& Concrete Composites, 29, 168-175.

European standard (2004) Eurocode 1 and 2: Basis of design and actions on structures and design of concrete structures. AFNOR.

Faber, M.H. \& Stewart, M.G. (2003) Risk Assessment for Civil Engineering Facilities: Critical Overview and Discussion, Reliability Engineering and System Safety, 80(2), 173-184.

Ferguson, M. E. (1998) Opti-OWECS, Final Report, Vol. 4: A typical design solution for an offshore wind energy conversion system, Tech. Rep. OPTI-OWECS, Institute for Wind Energy, Delft University of Technology.

Feser, F., Rockel, B., von Storch, H., Winterfeldt, J. \& Zahn, M. (2011) Regional Climate Models Add Value to Global Model Data: A Review and Selected Examples, Bulletin of the American Meteorological Society, 92(9), 1181-1192.

Frangopol, D.M. (2010) Life-cycle performance, management, and optimization of structural systems under uncertainty: Accomplishments and challenges. In H. Furuta, D.M. Frangopol, \& M. Shinozuka, editors, Safety, Reliability and Risk of Structures, Infrastructures and Engineering Systems, 38-60.

Ginger, J. D., Henderson D. J., Leitch, C. J. \& Boughton, G.N. (2007) Tropical Cyclone Larry: Estimation of wind field and assessment of building damage. Australian Journal of Structural Engineering, 7(3), 209-224.

Greenberg, M.R., Lahr, M. \& Mantell, N. (2007) Understanding the Economic Costs and Benefits of Catastrophes and Their Aftermath: A Review and Suggestions for the U.S. Federal Government, Risk Analysis, 27(1), 83-96.

Gsänger, S. \& Pitteloud, J. D. (2012) 2011 Report, The World Wind Energy Association, URL www.wwindea.org. 
Hall, J.W., Brown, S., Nicholls, R.J., Pidgeon, N.F. \& Watson, R.T. (2012), Proportionate Adaptation, Nature Climate Change, 2, 833-834.

Hallegatte, S. (2008) An Adaptive Regional Input-Output Model and its Application to the Assessment of the Economic Cost of Katrina, Risk Analysis, 28(3), 779-799.

Hammond, G., \& Jones C., (2011) Inventory of Carbon \& Energy (ICE) Version 2.0. [PDF] www.bath.ac.uk/mech-eng/sert/embodied/ (28th January 2011).

Hansen, M. H. (2003) Improved modal dynamics of wind turbines to avoid stall-induced vibrations, Wind Energy, 6(2), 179-195.

Hardaker, J.B., Fleming, E. \& Lien, G. (2009) How Should Governments Make Risky Policy Decisions?, Australian Journal of Public Administration, 68(3), 256-271.

Hardy, T.A, Mason, L.B. \& Astorquia, A. (2004) Queensland climate change and community vulnerability to tropical cyclones - ocean hazards assessment - stage 3: the frequency of surge plus tide during tropical cyclones for selected open coast locations along the Queensland east coast. State of Queensland, Australia

Hau, E. (2006) Wind Turbines: Fundamentals, Technologies, Applications, Economics, $2^{\text {nd }}$ edn., Springer, Berlin.

Heaton, M.J., Katzfuss, M., Ramachandar, S., Pedings, K., Gilleland, E., MannshardtShamseldin, E. \& Smith, R.L. (2011) Spatio-temporal models for large-scale indicators of extreme weather. Environmetrics, 22(3), 294-303.

Henderson, D.J. \& Ginger J.D. (2007) Vulnerability Model of an Australian High-Set House Subjected to Cyclonic Wind Loading, Wind and Structures, 10(3), 269-285.

Holden, R., Val, D.V., Burkhard, R. \& Nodwell, S. (2013) A network flow model for interdependent infrastructures at the local scale. Safety Science, 53, 51-60.

IA (2008) Outline of Infrastructure Australia's Prioritisation Methodology, Infrastructure Australia, Australian Government, Canberra, 24 September 2008.

IPCC (2000) Emission Scenarios. Special Report of the Intergovernmental Panel on Climate Change. Cambridge University Press, UK. 
IPCC (2007) Climate change 2007: Synthesis report. Contribution of working groups I, II and III to the fourth assessment report on intergovernmental panel on climate change. In: Pachauari RK, Reisinger A, editors (Core writing team). Geneva (Switzerland).

IPCC (2012) Managing the Risks of Extreme Events and Disasters to Advance Climate Change Adaptation. A Special Report of Working Groups I and II of the Intergovernmental Panel on Climate Change [Field et al. (eds.)], Cambridge University Press, Cambridge, United Kingdom and New York, NY, USA.

Jensen, J. J., Olsen, A. S. \& Mansour, A. E. (2011) Extreme wave and wind response predictions, Ocean Engineering, 38(17-18), 2244-2253.

Jones, P. D., Kilsby, C. G., Harpham, C., Glenis, V. \& Burton, A. (2010) UK Climate Projections science report: Projections of future daily climate for the UK from the Weather Generator, University of Newcastle, UK.

Jonkman, J., Butterfield, S., Musial, W. \& Scott, G. (2009) Definition of a 5MW reference wind turbine for offshore system development, Tech. Rep. NREL/TP-500- 38060, National Renewable Energy Laboratory, Golden, Colorado, USA.

Jordaan, I. (2005) Decisions Under Uncertainty: Probabilistic Analysis for Engineering Decisions, Cambridge University Press.

Kilsby, C.G., Jones, P.D., Burton, A., Ford, A.C., Fowler, H.J., Harpham, C., James, P., Smith, A. \& Wilby, R.L. (2007) A daily weather generator for use in climate change studies. Environmental Modelling \& Software, 22(12), 1705-1719.

Knutson, T.R., McBride, J.L., Chan, J., Emanuel, K., Holland, G., Landsea, C., et al. (2010) Tropical cyclones and climate change, Nature Geoscience, 3(3), 157-63.

Mehta, P.K. (2004) High-performance, high-volume fly ash concrete for sustainable development. In: International Workshop on Sustainable Development and Concrete Technology, 314 , Beijing.

Lomborg, B. (2009) Global Crises, Global Solutions, Cambridge University Press, Cambridge, UK.

Lucio, P.S., Silva, A.M. \& Serrano, A.I. (2010) Changes in occurrences of temperature extremes in continental Portugal: a stochastic approach. Meteorological Applications, 17(4), 404-418. 
Maddocks (2011) The Role of Regulation in Facilitating or Constraining Adaptation to Climate Change for Australian Infrastructure, Report for the Australian Department of Climate Change and Energy Efficiency, Maddocks.

Marino, E., Borri, C. \& Lugni, C. (2011a) Influence of wind-waves energy transfer on the impulsive hydrodynamic loads acting on offshore wind turbines, Journal of Wind Engineering and Industrial Aerodynamics, 99(6-7), 767-775.

Marino, E., Borri, C. \& Peil, U. (2011b) A fully nonlinear wave model to account for breaking wave impact loads on offshore wind turbines, Journal of Wind Engineering and Industrial Aerodynamics, 99(4), 483-490.

Mason, M., Phillips, E., Okada, T. \& O’Brien, J. (2012) Analysis of Damage to Buildings Following the 2010/2011 East Australian Floods, NCCARF, Griffith University, Australia.

McCaffrey, M., Goggins, J. \& Baylor, G. (2010) The use of embodied energy and carbon as indicators of the environmental impact of reinforced concrete structures in Ireland. Bridge and Concrete Research in Ireland. Cork, September 2010. Cork, Ireland.

Mendelsohn, R., Emanuel, K., Chonabayashi, S. and Bakkensen, L. (2012) The impact of climate change on global tropical cyclone damage, Nature Climate Change, 2, 205-209.

Mudersbach, C. \& Jensen, J. (2010) An advanced extreme value model for evaluating storm surge heights considering systematic records and sea level rise scenarios. Proceedings of the $32^{\text {nd }}$ Conference on Coastal Engineering, Shanghai, China, 2010.

Mullard, J.A. \& Stewart, M.G. (2011) Corrosion-Induced Cover Cracking: New Test Data and Predictive Models, ACI Structural Journal, 108(1), 71-79.

Mullard, J.A. \& Stewart, M.G. (2012) Life-Cycle Cost Assessment of Maintenance Strategies for RC Structures in Chloride Environments, ASCE Journal of Bridge Engineering, 17(2), $353-362$

Murphy, J. (1999) An Evaluation of Statistical and Dynamical Techniques for Downscaling Local Climate, Journal of Climate, 12(8), 2256-2284.

Murphy, J. M., Sexton, D. M. H., Jenkins, G. J., Booth, B. B. B., Brown, C. C., Clark, R. T., Collins, M., Harris, G. R., Kendon, E.J., Betts, R. A., Brown, S. J., Humphrey, K. A., McCarthy, M. P., McDonald, R. E., Stephens, A., Wallace, C., Warren, R., Wilby, R. \& Wood, R. A. (2009). UK Climate Projections Science Report: Climate change projections, Met Office Hadley Centre, Exeter, UK. 
Murtagh, P. J., Basu, B. \& Broderick, B. M. (2005) Along-wind response of a wind turbine tower with blade coupling subjected to rotationally sampled wind loading, Engineering Structures, 27(8), 1209-1219.

NAS (1999) The Impact of Natural Disasters: A Framework for Loss Estimation, National Academy of Sciences, Washington, D.C.

Nguyen, M.N., Wang, X. \& Leicester, R.H. (2013) An Assessment of Climate Change Effects on Atmospheric Corrosion Rates of Steel Structures, Corrosion Engineering Science and Technology (in press).

Nigam, N. \& Narayanan, S. (1994) Applications of Random Vibrations, Springer-Verlag, Delhi.

OMB (1992) Guidelines and Discount Rates for Benefit-Cost Analysis of Federal Programs (Revised), Circular No. A-94, October 29, 1992, Office of Management and Budget, Washington, DC.

Paté-Cornell, E. (2002) Risk and Uncertainty Analysis in Government Safety Decisions, Risk Analysis, 22(3), 633-646.

Paté-Cornell, E. (2012) On "Black Swans" and "Perfect Storms": Risk Analysis and Management when Statistics are Not Enough, Risk Analysis, 32(11), 1823-1833.

Peters, G.P., R.M. Andrew, Boden, T., Canadell, J.G., Ciais, P., Quéré, C.L., Marland, G., Raupach, M.R. \& Wilson, C. (2013) The Challenge to Keep Global Warming Below $2^{\circ} \mathrm{C}$, Nature Climate Change, 3, 4-6.

Pitt, M. (2008) The Pitt Review: Learning lessons from the 2007 floods.

Quilligan, A., O’Connor, A. \& Pakrashi, V. (2012) Fragility Analysis of Steel and Concrete Wind Turbine Towers, Engineering Structures, 36, 270-282.

Quilligan, A. (2013) Fragility Analysis of Steel and Concrete Wind Turbine Towers, PhD Thesis, Trinity College Dublin.

Rackwitz, R. (2002) Optimisation and risk acceptability based on the life quality index, Structural Safety, 24, 297-331.

Randall, D.A., R.A. Wood, S. Bony, R. Colman, T. Fichefet, J. Fyfe, V. Kattsov, A. Pitman, J. Shukla, J. Srinivasan, R.J. Stouffer, A. Sumi \& K.E. Taylor (2007) Climate Models and Their Evaluation. In: Climate Change 2007: The Physical Science Basis. Contribution of 
Working Group I to the Fourth Assessment Report of the Intergovernmental Panel on Climate Change. Cambridge University Press, Cambridge, United Kingdom and New York, NY, USA.

Rashedi, A., Sridhar, I. \& Tseng, K.J. (2012) Multi-objective material selection for wind turbine blade and tower - Ashby's approach, Materials \& Design, 37(2012), 521-532.

Rose, A. (2004) Economic Principles, Issues, and Research Priorities in Hazard Loss Estimation, in Modelling Spatial and Economic Impacts of Disasters, Y. Okuyama and S. Chang (eds.), Springer-Verlag, Berlin, 13-36.

Saetta, A., Scotta, R. \& Vitaliani, R. (1993) Analysis of chloride diffusion into partially saturated concrete, ACI Materials Journal, 90, 441-451.

Sánchez-Silva, M. \& Rosowsky, D.V. (2008) Structural reliability and risk in the developing world and its relationship with sustainability, ICE - Structures, 161, 189-198.

Schmitt, G. (2009) Global Needs for Knowledge Dissemination, Research, and Development in Materials Deterioration and Corrosion Control, World Corrosion Organization, New York, May 2009.

Singh, A. N. (2007) Concrete construction for wind energy towers. Indian Concrete Journal, 81, 43-49.

Stern, N. (2007) The Economics of Climate Change: The Stern Review, Cambridge University Press, Cambridge, UK.

Stewart, M.G. \& Melchers, R.E. (1997) Probabilistic Risk Assessment of Engineering Systems. London. Chapman \& Hall.

Stewart, M.G. \& Peng, J., (2010) Life cycle cost assessment of climate change adaptation measures to minimise carbonation-induced corrosion risks. International Journal of Engineering under Uncertainty: Hazards, Assessment and Mitigation, 2(1-2), 35-46.

Stewart, M.G., Ellingwood, B.R. \& Mueller, J. (2011) Homeland Security: A Case Study in Risk Aversion for Public Decision-Making, International Journal of Risk Assessment and Management, 15(5/6), 367-386.

Stewart, M.G. \& Wang, X. (2011) Risk Assessment of Climate Adaptation Strategies for Extreme Wind Events in Queensland, CSIRO Climate Adaptation Flagship, Canberra, May 
2011. Also Risk Assessment of Climate Adaptation Strategies for Australian Housing Subject to Extreme Wind Events, Climatic Change (in review).

Stewart, M.G., Wang, X. \& Nguyen, M. (2011) Climate Change Impact and Risks of Concrete Infrastructure Deterioration, Engineering Structures, 33(4),1326-1337.

Stewart, M.G., Wang, X. \& Nguyen, M. (2012a) Climate Change Adaptation for Corrosion Control of Concrete Infrastructure, Structural Safety, 35, 29-39.

Stewart, M. G., Wang, X. \& Willgoose, G.R. (2012b) Indirect Cost and Benefit Assessment of Climate Adaptation Strategies for Extreme Wind Events in Queensland. Published by CSIRO, Canberra, May 2012.

Sunstein, C.R. (2002) The Cost-Benefit State: The Future of Regulatory Protection, ABA Publishing, American Bar Association, Chicago.

Struble, L. \& Godfrey, J. (2004) How sustainable is concrete?, In: International Workshop on Sustainable Development and Concrete Technology, 201-211, Beijing.

Susskind, L. (2010) Responding to the Risks Posed by Climate Change: Cities Have No Choice but to Adapt, Town Planning Review, 81(10), 217-235.

Val, D.V. \& Stewart, M.G. (2003) Life Cycle Cost Analysis of Reinforced Concrete Structures in Marine Environments, Structural Safety, 25(4), 343-362.

Vestas (2004) General Specification, V90 - 3MW, Vestas Wind Systems, URL http: //www.vestas.com/.

Vestas (2005) General Specification, V90 - 1.8/2 MW (Optispeed Wind Turbine), Vestas Wind Systems, URL http://www.vestas.com/.

VG (2007) Infrastructure and climate change risk assessment for Victoria, Report to the Victorian Government, March 2007.

Walker, G.R. (2011) Comparison of the Impacts of Cyclone Tracy and the Newcastle Earthquake on the Australian Building and Insurance Industries, Australian Journal of Structural Engineering, 11(3), 283-293.

Wang, C-H. \& Wang, X. (2009) Hazard of Extreme Wind Gusts in Australia and Its Sensitivity to Climate Change, CSIRO National Research Flagship Climate Adaptation, May 2009. 
Wang, X., Stewart, M.G. \& Nguyen, M. (2012) Impact of Climate Change on Corrosion and Damage to Concrete Infrastructure in Australia, Journal of Climatic Change, 110(3-4), 941947.

Wang, C-H. \& Wang, X. (2012) Vulnerability of timber in ground contact to fungal decay under climate change, Climatic Change, 115(3-4), 777-794

Wigley, T.M.L., Richels, R. \& Edmonds, J.A. (1996) Economic and environmental choices in the stabilization of atmospheric $\mathrm{CO}_{2}$ concentrations. Nature, 379, 240-243

World Commission on Environment and Development (2007) Our common future. Oxford University Press, Oxford.

Worrell, E., Price, L., Martin, N., Hendriks, C. \& Meida, L.O. (2001) Carbon dioxide emissions from the global cement industry. Annual Review of Energy and the Environment; 26, 303329.

Xu, Y.-P., Booij, M.J. \& Tong, Y.-B. (2010) Uncertainty analysis in statistical modeling of extreme hydrological events. Stochastic Environmental Research and Risk Assessment, 24(5), 567-578.

Yunovich, M., N. G. Thompson, T. Balvanyos \& L. Lave (2001) Corrosion Costs and Preventative Strategies in the United States, CC Technologies Laboratories, Inc. to Federal Highway Administration (FHWA). 